\title{
Nano-biotechnology, an applicable approach for sustainable future
}

\author{
Nikta Shahcheraghi ${ }^{1}$ (D) Hasti Golchin ${ }^{2} \cdot$ Zahra Sadri $^{2} \cdot$ Yasaman Tabari $^{3} \cdot$ Forough Borhanifar $^{2} \cdot$ Shadi Makani $^{2}$
}

Received: 28 July 2021 / Accepted: 30 December 2021 / Published online: 9 February 2022

(c) King Abdulaziz City for Science and Technology 2022

\begin{abstract}
Nanotechnology is one of the most emerging fields of research within recent decades and is based upon the exploitation of nano-sized materials (e.g., nanoparticles, nanotubes, nanomembranes, nanowires, nanofibers and so on) in various operational fields. Nanomaterials have multiple advantages, including high stability, target selectivity, and plasticity. Diverse biotic (e.g., Capsid of viruses and algae) and abiotic (e.g., Carbon, silver, gold and etc.) materials can be utilized in the synthesis process of nanomaterials. "Nanobiotechnology" is the combination of nanotechnology and biotechnology disciplines. Nano-based approaches are developed to improve the traditional biotechnological methods and overcome their limitations, such as the side effects caused by conventional therapies. Several studies have reported that nanobiotechnology has remarkably enhanced the efficiency of various techniques, including drug delivery, water and soil remediation, and enzymatic processes. In this review, techniques that benefit the most from nano-biotechnological approaches, are categorized into four major fields: medical, industrial, agricultural, and environmental.
\end{abstract}

Keywords Nanotechnology $\cdot$ Nano-biotechnology $\cdot$ Nanomaterial $\cdot$ Nano-therapies

\section{Introduction}

The development process of a sustainable future generally consists of methods that ensure the satisfaction of future needs, while fulfills the current generation's requirements (Raghav et al. 2020). To obtain a proper overview of

Nikta Shahcheraghi

n.shahcheraghi@usc.ac.ir

Hasti Golchin

hastigolchin78@gmail.com

Zahra Sadri

zahrasadri7076@gmail.com

Yasaman Tabari

tabari.yasaman@gmail.com

Forough Borhanifar

forough.borhanifar@khu.ac.ir

Shadi Makani

shadimakani.sham1997@gmail.com

1 Department of Engineering, University of Science and Culture, Tehran, Iran

2 Faculty of Biological Sciences, Kharazmi University, No.43.South Moffateh Ave., 15719-14911 Tehran, Iran

3 Faculty of Sciences and Advanced Technologies, Science and Culture University, 1461968151 Tehran, Iran upcoming demands in the future, it is important to anticipate future stressors (e.g., climate change) (Iwaniec et al. 2020). Since nanotechnology is applicable in various majors, it is expected that nano-based techniques will take a key role in a sustainable future (Raghav et al. 2020), along with making substantial impacts on the universal economic situation due to their wide range of applications in variant industries (Adam and Youssef 2019). The unification of diverse fields in science, Inspired by the oneness of nature, is one of the most noticeable subject matters now in the early twentyfirst century. Merging four massively operational fields of science has received great attention in recent decades: nanotechnology, biotechnology, information technology, and cognitive sciences (NBIC), which are known as "convergent technologies" (Roco and Bainbridge 2013). Non-renewable sources don't seem efficient for providing large amounts of energy required in various industrial technologies. Convergent technologies are considered as a remedy for this issue. For instance, several nano-based technologies, which consume biological-renewable energy sources, have been introduced (Zhironkin et al. 2019). The unification of material on nanoscale makes the mentioned combination of multiple technologies possible. Hence, nanotechnology plays a critical role in NBIC advancement (Roco and Bainbridge 2013). According to the definition set by National Nanotechnology 
Initiatives in 1999, Nanotechnology is an advanced area of research that allows for the production of a wide class of materials in the nanoscale range (less than $100 \mathrm{~nm}$ ) to make use of size-and structure-dependent properties and phenomena (Luo et al. 2020). Although "nano" is defined as that which is less than $100 \mathrm{~nm}$ in size, the use of this definition in the biomedical field is less strict and instead may encompass particles up to $1000 \mathrm{~nm}$ in size (Landowski et al. 2020). Nanotechnology has a wide range of applications, including Agricultural usages (Ndlovu et al. 2020), biofuel production (Zahed et al. 2021a), cancer Immunotherapy (Goracci et al. 2020), carbon capture (Zahed et al. 2021b) and biomarker detection like nanobiochips, nanoelectrodes, or nanobiosensors (Bayda et al. 2020). Nanomaterials (NMs) are chemical substances or materials that are manufactured and used at a very small scale, i.e., $1-100 \mathrm{~nm}$ in at least one dimension. NMs are categorized according to their dimensionality, morphology, state, and chemical composition (Saleh 2020). NMs can be used for rapid extraction of RNA of the novel coronavirus (Kailasa et al. 2021). Expanding nanoscience through various branches can eventually enhance the intelligence and capability of individuals, solve various social issues, cure numerous diseases, and generally improve the quality of mankind's life in the long term (Roco and Bainbridge 2013). Deploying nanotechnology into biotechnology will help the commercialization process of nano-based techniques and make them more practical in the industry (Maine et al. 2014). The idea of developing interdisciplinary research (IDR) (Jang et al. 2018) in science presents a promising landscape of the future, in which human intelligence has reached such high levels that the term "superhuman" would be more proper for humankind. According to the Israeli philosopher Harari, with the appearance of a highly technologically advanced society, only individuals with great intelligence and technological advancements can survive through natural selection in society. He states that superhumans will be produced by society eventually, considering the logic of social Darwinism, and this will be a remarkable phenomenon of the twenty-first century (Mantatov et al. 2019). One massive application of nanobiotechnology is enhancing the efficiency of various therapies (Table 1). The application of nanobiotechnology in delivering chemical drugs or gene modifying agents to their target cells will increase the efficiency of the treatments and reduce the side effects remarkably. Within the previous two decades, RNA-based therapeutic methods, including messenger RNA (mRNA), microRNA, and small interfering RNA (siRNA), have been supremely developed. These therapeutic approaches are expected to be operative in the treatment and prevention of various diseases, such as cancers, genetic disorders, diabetes, inflammatory diseases, and neurodegenerative diseases (Lin et al. 2020). In the case of cancers, conventional therapies (surgery, chemotherapy, and irradiation) may cause severe side effects to patients, plus they are often inefficient for disease treatment (Hager et al. 2020). Loading anti-cancer drugs into nanomaterials provides a nano-based drug delivery system that detracts the side effects. Platinum $(\mathrm{Pt})$ compounds are one of the most common anti-cancer drugs since 1978. Pt drugs directly aim at the DNA of the targeted cells, thus covering up the defects of the malformed DNA repair mechanisms in cancerous cells. Encapsulating Pt drugs into liposomes constructs a nano-based drug delivery system for treating cancers (Rottenberg et al. 2021). Gold nanoparticles (AuNPs) are advantageous options for cancer treatment and diagnosis. AuNPs are created in the size range between 1 and $150 \mathrm{~nm}$ and in various shapes, including nanorods (AuNRs), nanocages, nanostars, and nanoshells (AuNSs). AuNPs consist of high rates of biocapability and exhibit controlled patterns of medicine release in the drug delivery process. AuNPs consist of conduction electrons on their surfaces which get excited by certain wavelengths of light. This feature enables AuNPs to adsorb light and produce heat that is fatal to cells. Destroying the cancerous cells with the heat released under irradiation is called photothermal therapy (PTT) or photodynamic therapy (PDT) (D'Acunto et al. 2021).

On the other hand, RNA-based therapies can regulate the expression of immune-relevant genes, therefore increasing anti-tumor immune responses directly. Several nanomaterials have been introduced that can deliver nucleic acid therapeutics to tumors and immune cells (Lin et al. 2020). There are biomimetic strategies for providing a co-delivery system that is capable of supporting both chemical and RNA-based therapies (Liu et al. 2019). Considering RNAs as therapeutic agents or drug targets requires precise knowledge about the 3D structure of specific RNAs. There are reliable algorithms for pronging the second structure of RNAs, but the tertiary architecture which determines the RNA's functions is quite challenging to anticipate. Bioinformatics provides several methods for predicting the tertiary structures of RNAs such as Vfold, iFoldRNA, 3DRNA, and RNAComposer. They all face particular hurdles, but it should be noted that the field of computational RNA structure anticipation, has a bright future (Biesiada et al. 2016). RNA-based vaccines are quite impressive immunotherapeutic tools in cancer therapies. However, the in vivo delivery of synthesized mRNAs could face some obstacles. Encrusting mRNAs with a lipid-polyethylene glycol (lipid-PEG) shell increases the mRNA delivery rate up to $95 \%$ more than the conventional nanoparticlefree mRNA vaccines (Islam et al. 2021).

In RNA-based nano-techniques, utilizing large-sized RNAs faces several difficulties. Wang et al. have reported an interesting method of using gold nanoparticles (enriched by expanded genetic alphabet transcriptions) to increase the effectiveness of detecting the large natural or artificially synthesized RNAs through an RNA nano-based labeling 


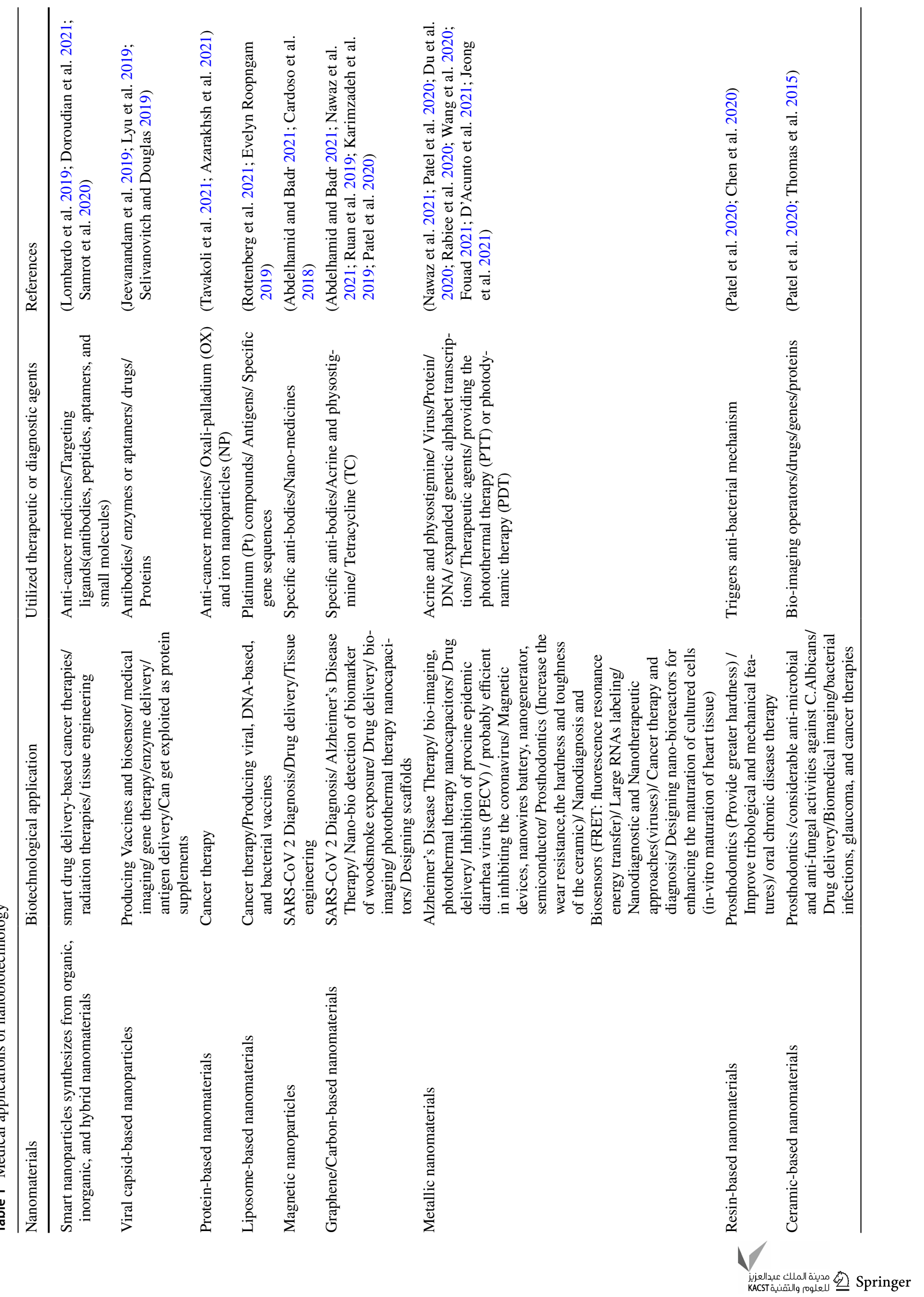




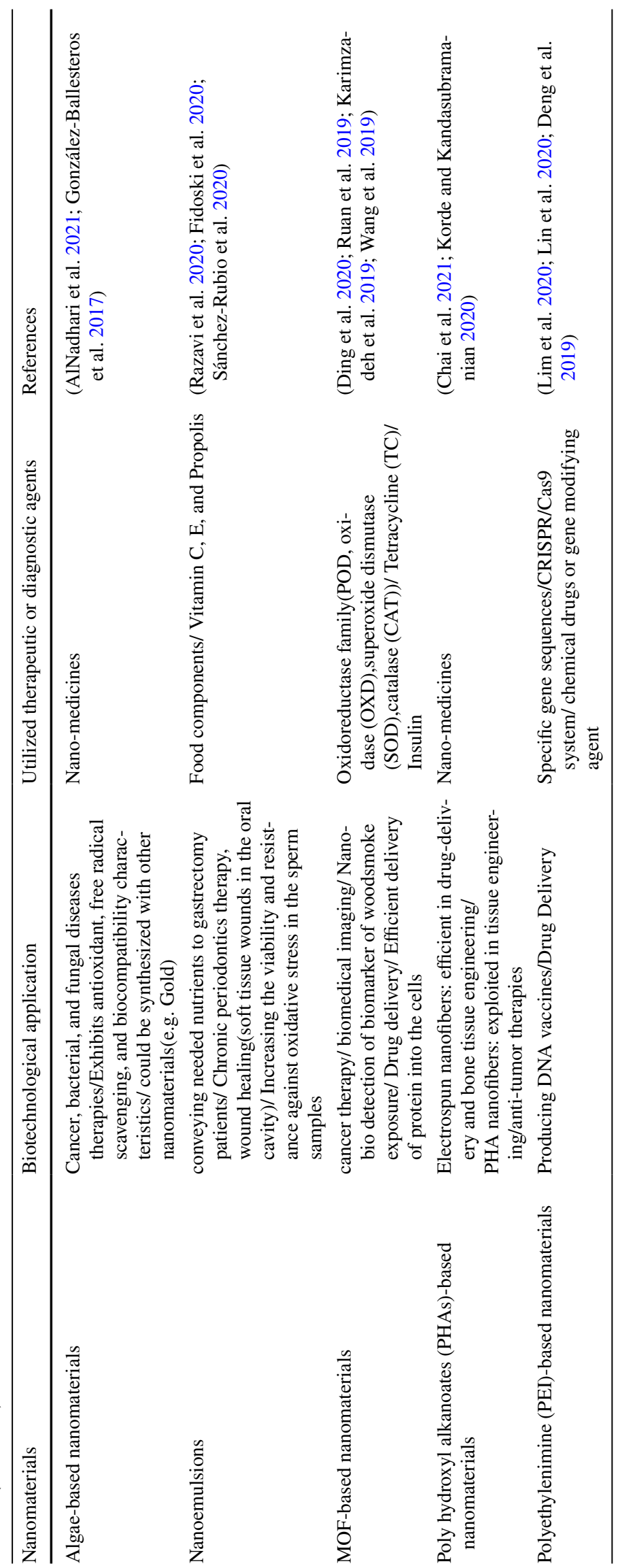


technique. These techniques are highly dependent on the conjugation between nanoparticles and RNAs (Wang et al. 2020). Since gene sequencing is of great importance, multiple biotechnology-based diagnostic tools, including quantitative PCR, DNA barcoding, next-generation sequencing, and imaging techniques are commonly currently used. These methods are considered economically advantageous, along with providing a reliable diagnosis. Incorporating nanobased sensors with mentioned tools increases the sensitivity and spatiotemporal resolution, which are two fundamental features of the gene sequencing process (Kumar et al. 2020). Designing nano-based devices for diagnosis of severe acute respiratory syndrome coronavirus 2 (SARS-CoV 2) has been promoted recently. Nanomaterials such as gold nanoparticles, magnetic nanoparticles, and graphene $(\mathrm{G})$ significantly increase the accuracy and decrease the required time and costs. Hence, render beneficial tools for viral detection more effective compared to the traditional techniques. Nanoparticles are specified via anti-bodies to identify particular antigens on the surface of the virus. Suspected samples from the patient, air, and surface can get examined by nano-based serological or molecular diagnosis methods (Abdelhamid and Badr 2021).

Nanomaterials can be utilized in the form of membranes. Chemically or physically synthesized nanomembranes remarkably advance the conventional water purification techniques (Lohrasebi and Koslowski 2019; Kim et al. 2020). Incorporating nanomembranes with bioreactors is the basis of the membrane bioreactor (MBR) technique, which is exploited in wastewater reclamation (Ma et al. 2018). Eliminating pollutant components from the environment is one of the main purposes of nanobiotechnology (Table 2). In the agricultural fields, nano-bio technologically modified pesticides and fertilizers notably prevent crop loss. Nano-based bioremediation processes have been developed to reduce soil pollutions and are expected to improve both environmental and agricultural approaches (Usman et al. 2020). Several studies are expanding the idea of producing nano plants that show better biological performances (e.g., photosynthesis) compared to natural plants (Marchiol 2018) (Table 3). Enzymes empowered by nanomaterials have rendered higher recovery and productivity rates and thus are potentially able to act spotless in different industrial techniques (Adeel et al. 2018; Zhang et al. 2021) (Table 4).

The objective of this study is to review the applications of nanoscience in enhancing the efficiency of biotechnological methods (Fig. 1).

\section{Application of nano-based materials for drug delivery, therapeutic and diagnostic processes}

One recently promoted technique in the gene therapy field is the application of the CRISPR/Cas9 systems, which has been indicated to be highly effective in the treatment of monogenic disorders, non-monogenic disorders, and infectious diseases. Emerging studies have suggested that nanocarriers, which are created from Polymer polyethyleneimine (PEI), are more efficient in delivering CRISPR/Cas9 systems to targeted cells compared to the viral carriers (Deng et al. 2019). Gene mutation-related diseases such as cancers and human immunodeficiency viruses are potentially treated by DNA-based vaccines. This type of vaccine enhances disease symptoms by delivering specific gene sequences-which are embedded in plasmids- to targeted cells. Despite having clinical utilization, DNA vaccines face limitations in delivering their genetic cargos to the target cells. Designing efficient nano-delivery systems will eliminate such deficiencies PEI (Lim et al. 2020). Virus-like nanoparticles (Jeevanandam et al. 2019) seem to form applicable nanocarriers for this purpose (Fig. 2).

Nanomaterials used in cancer diagnosis can be mainly divided into contrasting agents (magnetic, iron oxide and gold nanoparticles) and fluorescent agents (quantum dots). Some nanocarriers have inherent optical properties (such as carbon nanotubes, gold and magnetic nanoparticles) that can be converted into high energy to cells for destruction and can serve as nanotheranostics (Barani et al. 2021).

Nanomaterials used in smart drug delivery-based cancer therapies are categorized as organic and inorganic materials. Micelles, vesicles, multilamellar liposomes, and solid lipid nanoparticles are some examples of self-assembled organic nanomaterials. Other organic materials are not capable of self-assembling and need to be synthesized, such as nanotubes and dendrimers. Gold nanoparticles, quantum dots, mesoporous silica nanoparticles, and superparamagnetic iron oxide nanoparticles (SPIONs) are classified as inorganic nanomaterials (Lombardo et al. 2019). SPIONs are vastly utilized in therapeutic approaches, including cancer therapy, radiation therapy, and tissue engineering. SPIONs are synthesized through different physical, chemical, and biological methods. Bacteria and plants are the biomaterials upon which the biological method is based (Samrot et al. 2020). Nanoparticles containing both organic and inorganic materials (hybrid nanoparticles) have been indicated to be highly efficient, as well (Lombardo et al. 2019). Embedding targeting ligands (e.g., antibodies, peptides, aptamers, and small molecules) on the surface of nanoparticles assures the delivery of medicines to specific sites in the body, such as tumor tissues. The mentioned process is called: "targeted drug delivery system" (Doroudian et al. 2021). There are two types of targeting delivery: passive targeting and active targeting. In the passive form, the high aggregations of medicines at the tumor sites are related to the nano-scaled size of the nanocarriers. The tight junctions between epithelial cells of the vessel tissues prevent the nanoparticles from exiting the vessel. The cancerous cells loosen the tight junctions 


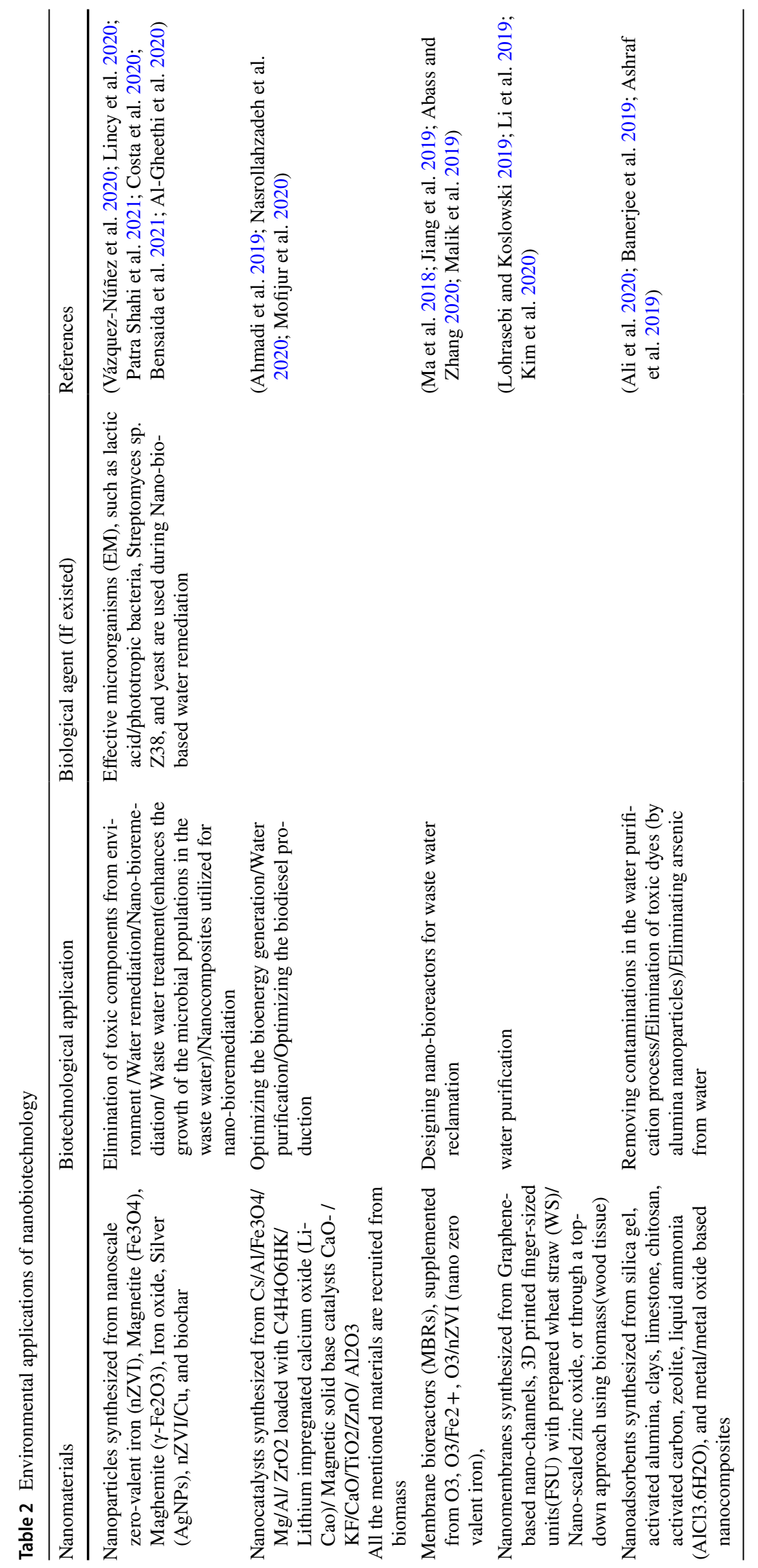




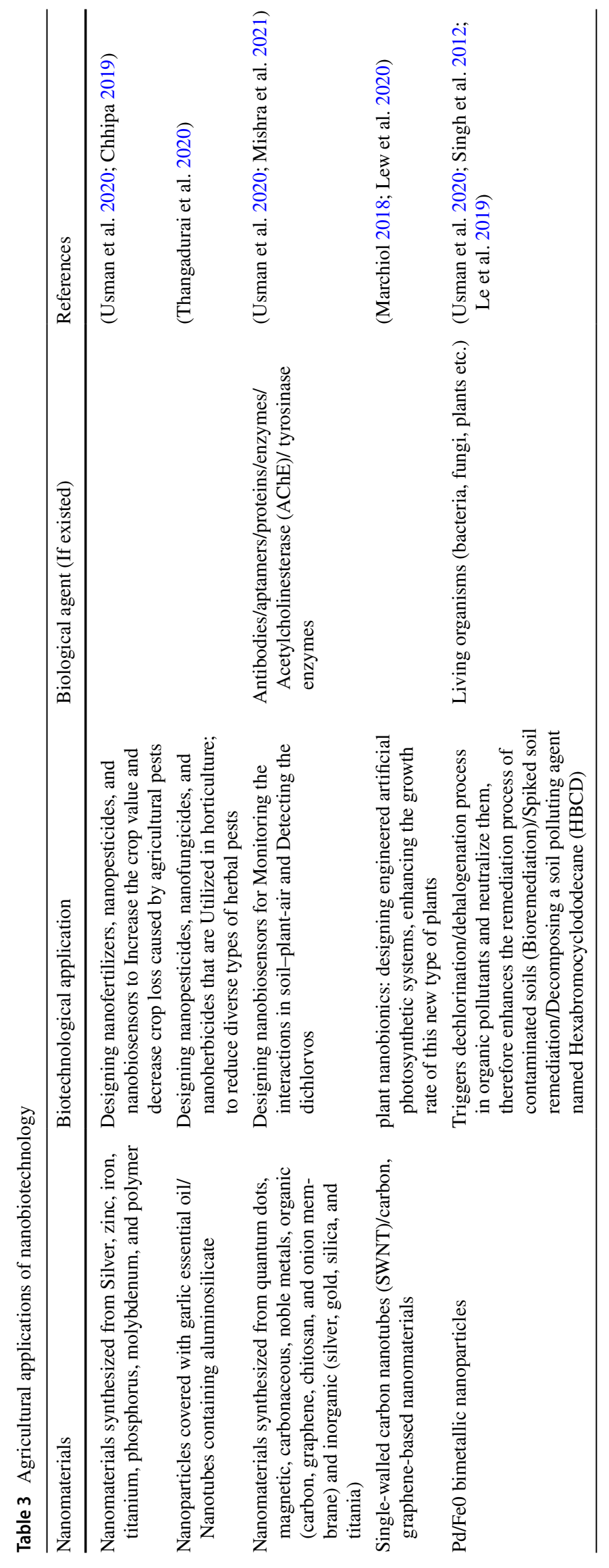




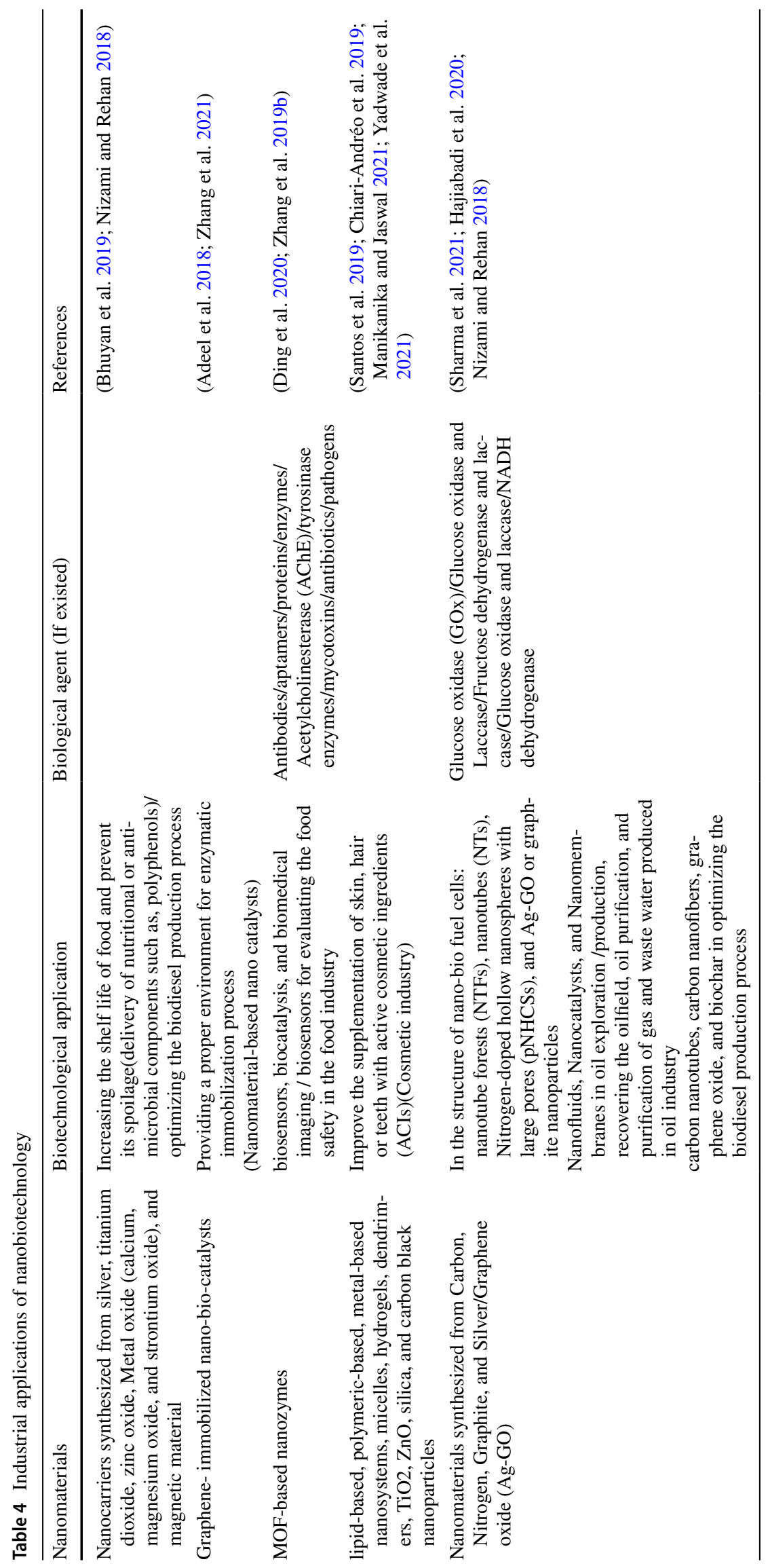




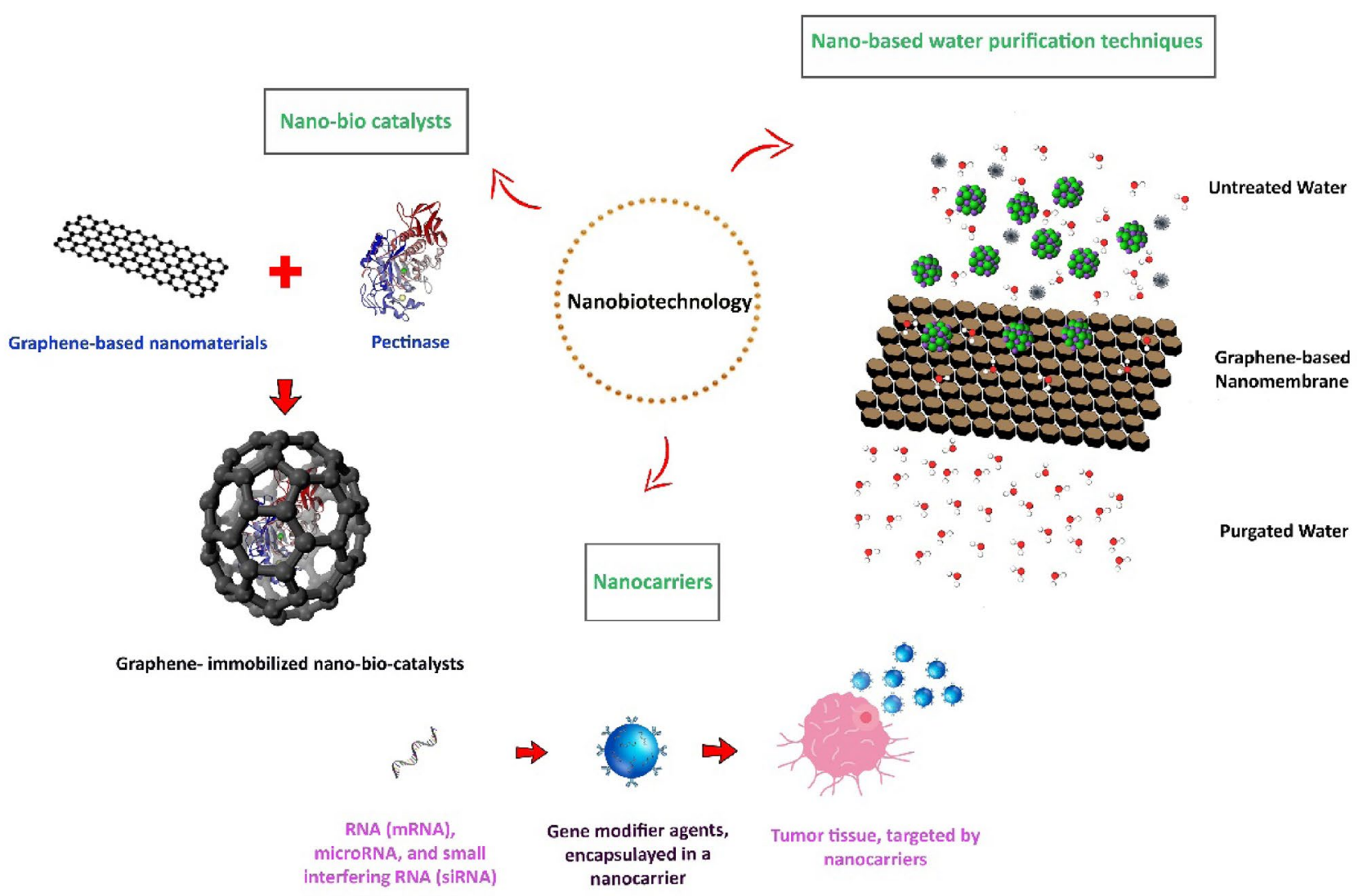

Fig. 1 Diverse Applications of Nanobiotechnology: multiple techniques, including Drug delivery-based therapies, remediating processes, and industrial nano-bio catalysts benefit from nano-scaled particles

of the adjacent vessels. Therefore, nanocarriers can pass through the vessel and get into the tumor site. The targeting ligands incorporated with nanoparticles are not responsible for the passive targeting action. The binding between the targeting ligands and the particular receptors on the cancerous cells-which are exclusively found on the surface of the tumor cells- causes a more precise drug delivery, which is known as active targeting (Doroudian et al. 2019). Although drug-loaded nanoparticles efficiently carry the medicines to target cites, according to the in-vivo studies, these nanoparticles might not be quite biodegradable. Hence using such nanoparticles could lead to toxicities and side effects. It is worth mentioning that Zhou et al. have developed biodegradable nanoparticles using poly (aspartic acid) (PASP) microtube, a thin $\mathrm{Fe}$ intermediate layer, and a core of $\mathrm{Zn}$ (Zhou et al. 2019).

Nano-based drug delivery systems provide highly promising prospects for treating neurodegenerative disorders. It is reasonable to assume that treating neurological diseases by conventional drug delivery systems is extremely challenging due to the presence of the blood-brain barrier (BBB). The blood-brain barrier prevents the entrance of therapeutical agents to the central nervous system (CNS), therefore, making the conventional therapies inadequate. The blood-brain barrier provides a stable environment for the CNS and regulates the cell-to-cell interactions, which take place in the CNS. The dysfunction of the blood-brain barrier leads to severe neurodegenerative disorders (e.g., Parkinson's disease (PD), Alzheimer's disease (AD), amyotrophic lateral sclerosis (ALS), and multiple sclerosis (MS)). The blood-brain barrier is responsible for the proper functioning of the CNS, so naturally, it has a super-sensitive permeability. This feature of the blood-brain barrier is highly related to the tight junctions between the barrier's cells. Only 1-4 percent of most CNS medicines succeed in passing the blood-brain barrier. Nanoparticles are more likely to pass the barrier because of their nano-scaled size. Encapsulating drugs in nanoparticles can significantly increase the drug transmission rate through the blood-brain barrier (Furtado et al. 2018). For instance, graphene, metals, carbon-nanotubes, and metal-oxides are the nanomaterials that can get exploited in the treatment procedure of patients with Alzheimer's disease (AD). AD is caused by different genetic and environmental cues. Chemical and electrical malformations are observed in the brain of an $\mathrm{AD}$ patient. Acrine and physostigmine, which are conventional medicines for $\mathrm{AD}$, have

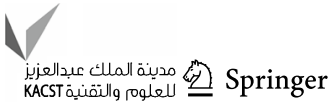




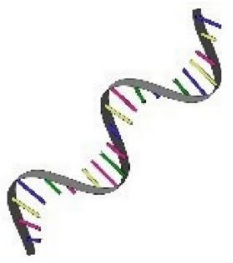

Therapeutic RNAs

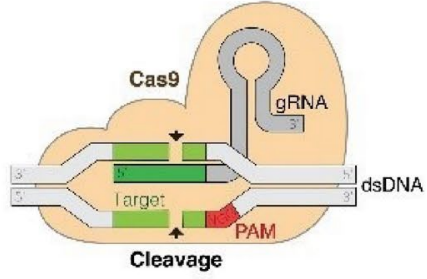

Crisper/Cas9 Systems
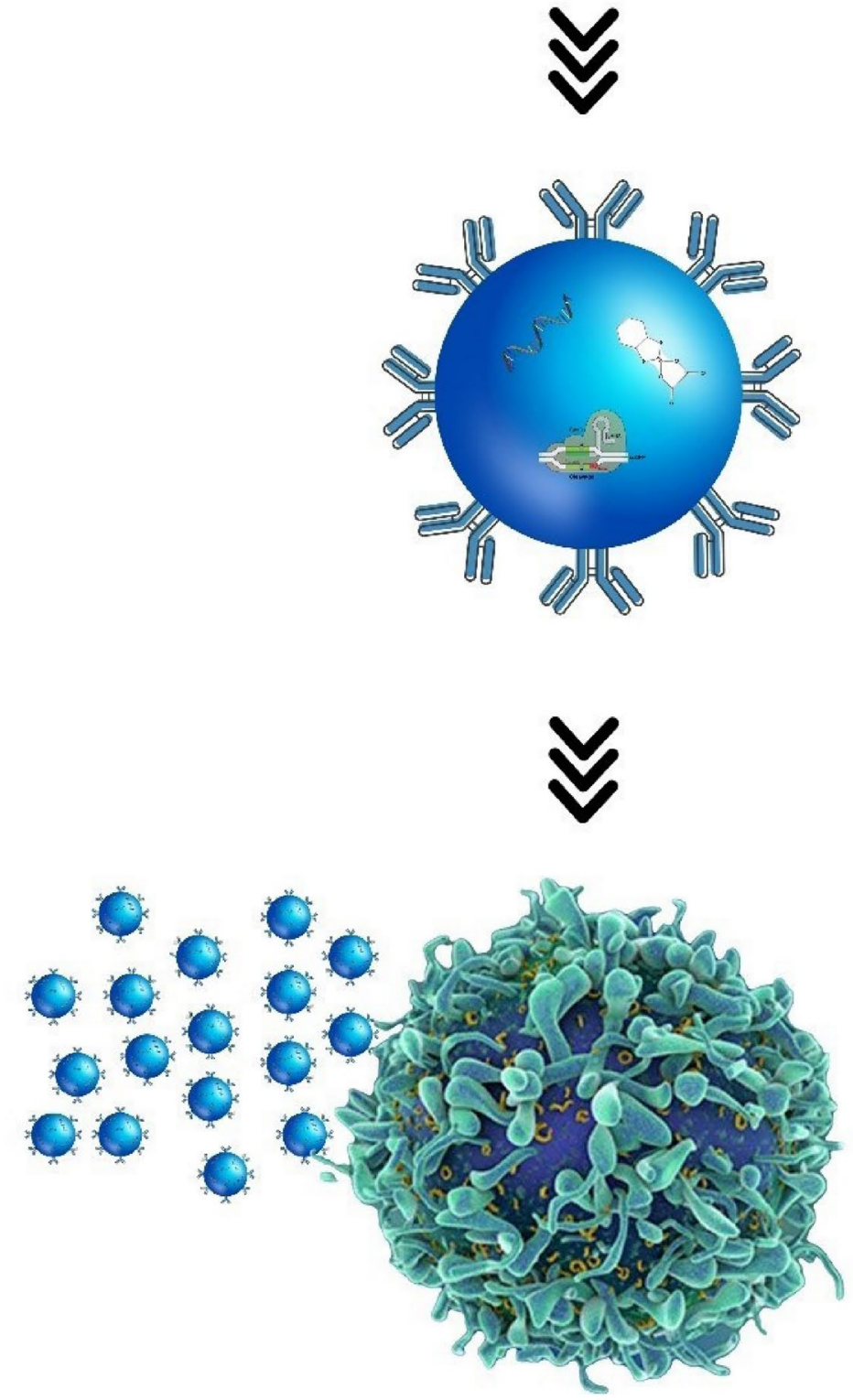

Nanoparticles can get loaded by diverse therapeutic agents
Nanoparticles target the cancerous tumor

Fig. 2 Encapsulating therapeutic agents within nanoparticles: embedding medicine or gene-modifying agents into the nanoparticles remarkably enhances the therapeutic efficiency along with diminishing potential side effects 
been proved to stimuli severe effects on the gastrointestinal tract and nervous system. Therefore, attention is drawn to nano-based therapies (Nawaz et al. 2021). Marcos-Contreras et al. have proposed that the augmentation of VCAM-1 ligands to the drug-loaded nanocarriers can significantly improve the cerebral accumulation rate of nanoparticles in inflamed brains (Marcos-Contreras et al. 2020) (Fig. 3).

Although nano-based medications of neurodegenerative disorders seem spotless theoretically, the internal environment of the body puts out several obstacles on the path of the medicine nano-delivering. For instance, lipid nanoparticles (LNPs) may safely carry their therapeutic cargos to the targeted cells, but if the drug needs to reach the cytoplasm, lipid nanoparticles are not capable of efficiently crossing the cell membrane. Small interfering RNAs (siRNAs) are delivered to hepatocytes via lipid nanoparticles, but only $2 \%$ of them accomplish reaching to the cytoplasm. It should be mentioned that big data and computational

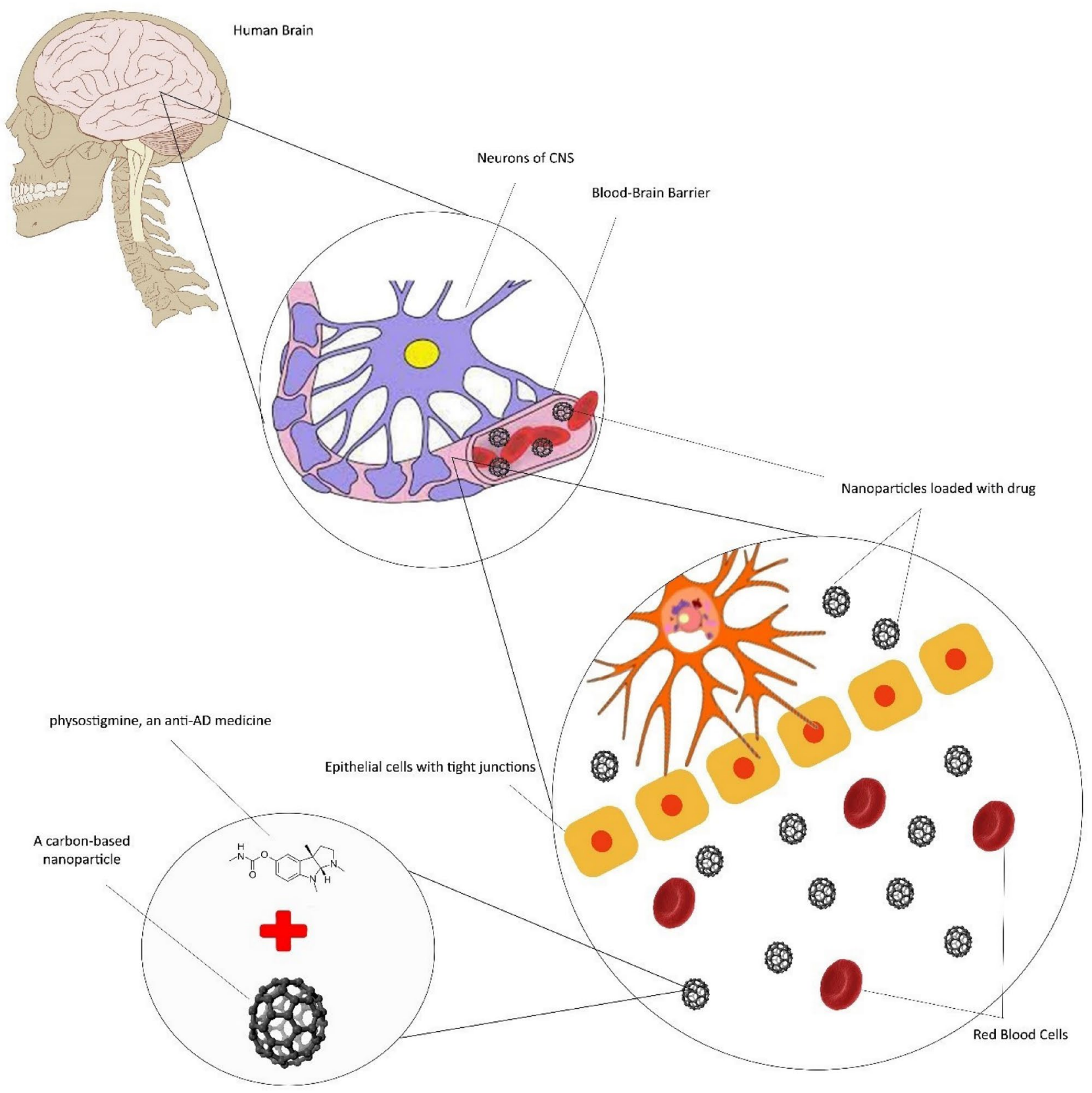

Fig. 3 Nano-based drug delivery in the therapies of neurodegenerative disorders: blood-brain barrier (BBB) is a noticeable obstacle for conventional medicines; however, drugs encapsulated within nano- particles efficiently penetrate through the BBB and reach the central nervous system (CNS) 
methods can help scientists to predict the in-vivo challenges of nano-drug delivery to design proper techniques to overcome them (Paunovska et al. 2019). Besides, bioinformatics provides tools for measuring the interaction rate between exploited nanomaterials and drug targets (Nawaz et al. 2021). Designing efficient nanomaterials is fundamental for nanotechnological approaches. Carbon nanotubes (CNTs) and graphene-based nanomaterials have been vastly utilized in nanotechnology during the last two decades (Kinloch et al. 2018). As a case in point, Single-walled carbon nanotubes (SWCNTs) are considered as excellent options for designing nano-based biomedical approaches, including but not limited to drug delivery systems. The most noticeable features of SWCNTs are their great photophysical properties (Farrera et al. 2017). Even though Carbon nanotubes (CNTs) and graphene-based nanomaterials have unique qualities such as high flexibility, they face some challenges in their load transfer capability, dispersion, and viscosity. Hence, creating more applicable and eco-friendly nanomaterials has drawn intense attention (Kinloch et al. 2018). AlNadhari et al. have introduced algae as a green and eco-friendly source of materials that can be used in nanoparticles. Algae-based nanoparticles in the biomedical field consist of therapeutical characteristics, such as antibacterial, anti-fungal, and anti-cancer features (AlNadhari et al. 2021). Milk-derived proteins such as $\beta$-lactoglobulin ( $\beta$-LG), lactoferrin (LF), and the caseins $(\mathrm{CN})$ are other biological alternatives for synthesizing nanocarriers. Anti-cancer medicines have been embedded into protein-based nanocarriers and successfully deteriorated cancerous tumors (Tavakoli et al. 2021). Azarakhsh et al. have demonstrated specific binding sites for the anti-cancer drug, Oxali-palladium (OX) and iron nanoparticles (NP) on the Beta-Casein $(\beta-\mathrm{CN})$. Hence, the Beta-Casein can perform as an efficient carrier for both agents (Azarakhsh et al. 2021). One common strategy in designing nanocarriers for cancer therapies is to create nanoparticles that can detect the vitamin or growth factor receptors on target cells. Cancerous cells usually over-express the receptors for such nutrients so that they can keep their high proliferation rate (Peer et al. 2020). Reprogramming the nutrient signaling and micropinocytosis of the cancer cells seriously affects the efficacy of Nano-particulate albumin-bound paclitaxel (nab-paclitaxel, nab-PTX); which is one of the most commonly prescribed nanomedicines (Li et al. 2021).

Antimicrobial peptides (AMPs) are short-chain, often cationic, peptides possessing several attributes which make them attractive alternatives to conventional antibiotics with $\mathrm{s}$ a low likelihood of resistance developing in target organisms (Meikle et al. 2021). Conjugation and functionalization of nanoparticles with potentially active antimicrobial peptides has added advantages that widen their applications in the field of drug discovery as well as a delivery system, including imaging and diagnostics (Mohid and Bhunia 2021).
Silver nanoparticles coated with zinc oxide (Ag@ $\mathrm{ZnO})$, can stimulate proliferation and migration of human keratinocytes, $\mathrm{HaCaT}$, with increased expression of Ki67 and vinculin at the leading edge of wounds. Interestingly, $\mathrm{Ag} @ \mathrm{ZnO}$ stimulates keratinocytes to produce the antimicrobial peptides hBD2 and RNase7, promoting antibacterial activity against both extracellular and intracellular Staphylococcus aureus isolated from wounds (Majhi et al. 2021).

Wound dressing is an important action against an injury. In recent years, nanotechnology has been combined with wound dressing techniques, and there are several new materials and techniques available for this action. The nanoparticles' dimensions make them suitable for penetrating into the wound. Thus, bioactive agents and drugs can be released locally (De Luca et al. 2021). Numerous synthetic and natural materials have been applied for wound healing; Hyaluronic Acid, as an illustration, is one of the most-used materials (Ahire and Dicks 2016).

In 2017 Polyethylene Oxide (PEO)-hyaluronic acid (HA) nanofibers as an inhibitor of Listeria monocytogenes infection (Ahire et al. 2017a). Gauze is a traditional wound dressing used to protect dermal wounds from bacterial infection. In a study in 2021, an antibacterial gauze was prepared by the combined use of antimicrobial peptides and AgNPs. The prepared antibacterial gauze showed excellent antibacterial activity against E.coli, S. enteritidis, S. aureus, and B. cereus and also exhibited good biocompatibility (Chen et al. 2021a, b). In 2014, Ahire and Dicks introduced 2,3-Dihydroxybenzoic Acid-Containing Nanofiber as a suitable nanomaterial for wound dressing as it prevents Pseudomonas aeruginosa infection (Ahire and Dicks 2014). To inhibit the growth of this microorganism, Copper-Containing Anti-Biofilm Nanofiber Scaffolds can be used too. Copper-containing nanoparticles have the potential of inhibiting Escherichia coli growth either (Ahire et al. 2016). Surfactin-loaded nanofibers are also a great candidate to be used in wound dressings or in the coating of prosthetic devices to prevent biofilm formation and secondary infections (Ahire et al. 2017b). In addition to nano-therapies, nano-diagnostic agents- metal nanoparticles- have been indicated to be highly applicable in the detection of viruses, including covid-19 (Fouad 2021). Several biotic [e.g., algae (AlNadhari et al. 2021) and viral capsid (Jeevanandam et al. 2019)] and abiotic [e.g., gold, silver, graphene oxide, and zin oxide (Fouad 2021)] nanomaterials have been reported to be applicable in biomedical processes. The combination of biotic and abiotic sources provides efficient nanomaterials as well. For example, the highly effective graphene-starch nanocomposites, are resulted from embedding graphene-based nanomaterials into the starch biopolymers (Mishra and Manral 2021). The delivery of therapeutics via nanoemulsions (NE) has shown striking results. Sánchez-Rubio et al. have successfully defeated deficiencies of vitamin E (e.g., hydrophobicity and 
low stability) by creating nanoemulsions comprising vitamin E. the sperm samples derived from the red deer's epididymal tissue was treated with the mentioned nanoemulsions and the sperms' viability and resistance against oxidative stress, was increased (Sánchez-Rubio et al., 2020). Jeong et al. have reported another growth-promoting method that elevates the maturation process of cultured cells. The mentioned technique aims to develop an extremely operational and costeffective bioreactor that enables in-vitro maturation of heart tissue. Next-generation stage-top incubator (STI) containing nano grooves patterned PDMS diaphragm (NGPPD) was designed to boost cell maturation and myogenic differentiation. The surface of NGPPD was covered with a slim layer of gold (Au) (Jeong et al. 2021). Microfluidic systems are proven to have applications in biological analysis, tissue engineering, etc. Embedding nanolitre volumes into microsized fluidic channels is the basis of the aforementioned technique (Valencia et al. 2020).

\section{Application of nanoparticles on bioreactors as contributory agents}

Since wastewater reclamation is a universal challenge and plays a major role in providing clean water for many people across the world, various techniques have been developed for this purpose. Among them, the application of membrane bioreactors (MBRs) in water purification has attracted great attention recently. In the MBR technique, the conventional activated sludge (CAS) process is incorporated with a filtration process provided by a physicochemical membrane (Ma et al. 2018). It has been shown that treating the mentioned membrane with nanoparticles in different types of MBR techniques can significantly improve the efficiency of the process (Abass and Zhang 2020; Jiang et al. 2019). The pharmaceutical industry produces one of the most pollutant wastewaters; which contains various amounts of organic compounds, including benzene, polynuclear aromatic hydrocarbons (PAHs), and heterocyclic, etc. these compounds have high Chemical Oxygen Demand (COD) and low degradability; which makes conventional biological treatments inefficient for treating them. However, applying $\mathrm{O}_{3}, \mathrm{O}_{3} / \mathrm{Fe}^{2+}$, $\mathrm{O}_{3} / \mathrm{nZVI}$ (nano zerovalent iron) processes in wastewater purgation has made noticeable signs of progress. Nano catalytic ozonation process $\left(\mathrm{O}_{3} / \mathrm{nZVI}\right)$ in a semi-batch reactor has the highest effect on advancing degradation amongst all (Malik et al. 2019). An experiment conducted in southern Tehran succeeded in removing the Methyl Tertio Butyl Ether (MTBE) and benzene from groundwater, using Fenton's chemical oxidation with stabilized nano zerovalent iron particles (S-NZVI) as a catalyst. The removal efficiency of MTBE and benzene were increased to $90 \%$ and $96 \%$, respectively, by reducing the $\mathrm{pH}$ of the reaction environment down to 3.2. Acidification of the environment decreased iron consumption as well (Beryani et al. 2017).

\section{Nano-bioremediation}

One green and cost-effective approach for treating the pollutant soils to reduce their toxicity is applying living organisms (bacteria, fungi, plants, etc.) through a process named: "bioremediation." Integrating bioremediation with nanoparticles increases the efficiency of the process (Usman et al. 2020). The technology of nano-remediation is a sustainable method to reduce the contaminants of the soil by various means (Yue et al.2021; Sajjadi et al. 2021; Lian et al. 2021). As an example, the reduction of $\mathrm{Cr}$ (VI) levels using this technology is known to be worthwhile in many aspects (Azeez et al. 2020; He et al. 2020). Chemically active nanoparticles can trigger the dechlorination/ dehalogenation process in organic pollutants and neutralize them, consequently. Even the toughest pollutants are targeted in this nano-bio-based remediation method. The time needed for the purgation of highly contaminated soils will be minimized by virtue of the mentioned technique (Usman et al. 2020). Iron oxide nanoparticles (NP) and $\mathrm{Fe}_{3} \mathrm{O}_{4}$ /biochar nanocomposites are vastly exploited in the synthesis of nanoparticles of nano-bioremediation (Patra Shahi et al. 2021). It is worth noting that nano zerovalent iron (nZVI) is an effective technology in the case of remediation that has been applied broadly in recent years due to high levels of reactivity for contaminants (Luo et al. 2021; Visentin et al. 2020; Ken and Sinha 2020; Hou et al. 2019; Zhu et al. 2019).

The bioremediation process can be used in water purification as well. Separating solid components from liquid waste is a necessary stage in the water remediation process. The fresh market waste may contain infectious components, which can seriously harm humans and plants. Hence, it is important to develop methods to collect, separate, and treat these adverse agents. Solid wastes in the wastewater contain high amounts of carbohydrates and proteins, and they provide matrices for the colonization of infectious organisms. Altogether, the presence of solid wastes improves the growth rate of pathogenic organisms. After solid matters got collected, they should be stored and treated immediately. The treatment process must not be delayed because the enriched environment of the solid wastes can easily get corrupted. One way to treat them is through triggering the fermentation and composting processes. Adding effective microorganisms (EM), such as lactic acid/phototropic bacteria and yeast, accelerates the conventional fermentation and composting processes used for the solid waste treatment (Al-Gheethi et al. 2020). Costa et al. have sequenced the whole genome of the strain Streptomyces sp. Z38, and detected growthpromoting, heavy metal-eliminating, and anti-microbial features within specific biosynthetic genes. Streptomyces sp. 
Z38 seems to be a suitable agent for bioremediation due to its ability to decompose heavy metals such as $\mathrm{Cr}$ (VI) and $\mathrm{Cd}$ (II). Costa et al. have supplemented the bioactive water (BW) extracted from Streptomyces sp. $\mathrm{Z} 38$ with $\mathrm{AgNO}_{3}$ additives and produced silver nanoparticles (AgNPs) that are capable of performing the bioremediation process (Costa et al. 2020). There are other effective nanomaterials exploited to reduce many pollutants from soil and wastewater. For instance, utilization of nano-manganese oxide to eliminate ZnII/CoII from water (Mahmoud et al. 2020), application of nano-semiconductors on water and their Photocatalytic effectiveness (Oliveira et al. 2021), nano-scaled Iron (II) sulfide exploited to reduce hexavalent chromium from soil (Tan et al. 2020), production of nanocomposite for eliminating viruses (Al-Attabi et al. 2019), and successful application of nano biosurfactants which cause no toxicity for the environment (Debnath et al. 2021). Nano-bioremediation as an emergent approach causes some concerns and benefits at the same time. It is possible that nanomaterials exploited in this method would be a threat to the organism populations that exist naturally in water bodies. On the other hand, new living organisms would be introduced through bioremediation. The mentioned two scenarios can potentially put the anthropogenic features of ecosystems in danger (Weijie et al. 2020). Concerning this problem, however, scientists are trying to apply new methods to remove nanoparticles from marine ecosystems via other technologies (Ebrahimbabaie et al. 2020).

\section{Designing nano-based water purification techniques, to overcome the problem of lack of clean water, across the world}

Waterborne diseases that cause almost 10-20 million deaths annually are considered crucial health-related issues. According to the World Health Organization and environmental protection agencies, the pollution level of several water bodies has long crossed the defined limitations. Thus, developing methods for purging water from adverse components is of great concern (Sahu et al. 2021). The water purification process profits extremely from nanobiotechnology. Nanoparticles are extremely efficient in eliminating pollutants (e.g., dye components) due to their nano-scaled size and increased surface areas. In the case of dye removal, magnetic nanoparticles have been proved to be proper candidates (Lohrasebi and Koslowski 2019). Nanoadsorbents such as silica gel, activated alumina, clays, limestone, chitosan, activated carbon, and zeolite are cost-effective and profitable options for eliminating the contaminating agents during water purification process (Ali et al. 2020).

Copper and copper compounds are potent biocides and have been utilized as a disinfectant for centuries due to their anti-microbial properties. It becomes more functional in its nano form and exhibits outstanding synergist, antifungal, and anti-bacterial effects (Bashir et al. 2021).

Copper nanoparticles have the potential of combination with other materials like Polyacrylonitrile (PAN) nanofibres and Polyethylene Terephthalate Filters to act more beneficial (Ahire and Neveling 2018; Nguyen et al. 2021).

Metallic nanomaterials, carbon-based nanomaterials, nanocomposites, and dendrimers are four major types of nanomaterials that can be applied in wastewater purgation (Murshid et al. 2021). Graphene-based nano-channels, which are inspired by aquaporin channels, have been utilized as water filters and are expected to enhance the water permeability and the salt rejection rate. It is worth noting that the efficiency of these filters can be affected by various factors. For example, it has been indicated that increasing the charges on the channel will decrease the water flow through the channel but, on the other hand, increase the ion rejection rate (Lohrasebi and Koslowski 2019). Carbon nanotubes (CNTs) have rendered noticeable results in eliminating the water contaminants, as well (Kutara et al. 2016).

The biosafety of water purification via finger-sized unit (FSU) has been certified by cellular and animal tests. In one study, Li et al. loaded 3D printed finger-sized units with prepared wheat straw (WS). To prepare WS for mentioned technique, the carbonized wheat straw (CWS) was adjusted with nano-scaled zinc oxide during an in-situ surface-modification process $(\mathrm{CWS} / \mathrm{ZnO})$. The resulted FSU was able to reduce bacteria, organic dyes, and heavy metal ions; therefore, elevating the purification efficiency. Since WS is one of the major agricultural wastes worldwide, applying it in water purification will not only cost very low but will reduce the air pollution which is caused by burning WS in many countries. The WS has a hallow, flexible, and electrical conductor structure. These features make WS a great candidate for enhancing water purification performance ( $\mathrm{Li}$ et al. 2019).

For designing a nano-based filtering membrane, nanoparticles don't always have to be chemically synthesized or externally applied on the membrane. An emerging study has suggested a top-down approach that uses biomass to provide a functional membrane for the purification of the emulsions. This method can be used massively in cleaning oily waters resulting from industrial or domestic activities. The biomass used in the mentioned technique is wood tissue. The lignin and hemicellulose fractions are removed sectionally, and therefore, a highly porous, flexible, and durable membrane is provided. Since the lignin is removed and there is no hydrophobia left, the resulting wood membrane consists of outstanding water-absorbing and anti-oil properties. The wood-nanotechnology-based membrane shows significant efficiency due to its numerous advantages, including being green, economical, easy to produce, durable, and having selective wettability (Kim et al. 2020). 
Rezaei et al. have synthesized a flower-shaped $\mathrm{ZnO} / \mathrm{GO} /$ $\mathrm{Fe}_{3} \mathrm{O}_{4}$ ternary nanocomposite through the co-precipitation method, which is considered a rather fast and easy synthesis approach. The mentioned nanocomposite improves the $\mathrm{ZnO}$ degradation through a performance with an efficiency that is more than two times greater than the efficiency of the methods using $\mathrm{ZnO}$ particles alone. Hence, the $\mathrm{ZnO} /$ $\mathrm{GO} / \mathrm{Fe}_{3} \mathrm{O}_{4}$ ternary nanocomposite seems to be an economical and time-saving approach for wastewater remediation (Rezaei et al. 2021).

It is worth noting that the vast uses of nanoparticles in different industrial products increase the risk of the inevitable release of nanoparticles into the environment, and therefore cause some concerns about the potential damages of nanobiotechnology. The urban wastewater seems to be highly exposed to industrial nanoparticles. The high concentrations of nanoparticles in the urban wastewater contaminate the sewage sludge, consequently. Wastewater treatment plants (WWTPs) are currently exploited to remove nanoparticles from wastewater and sewage sludge (Wang and Chen 2016). Nanoparticles synthesized and utilized in the industry can end up in marine ecosystems. Nanoparticles are developed from various chemical components such as carbon, silver, gold, and copper, which are potentially hazardous to live organisms. Since nanoparticles are extremely small in size, likely, they will easily enter the bodies of aquatic animals. It has been demonstrated that the accumulation of nanoparticles in the animal's body can cause severe morphological and behavioral deformities. Genetic materials of cells may undergo various changes as well (Gökçe 2021).

$\mathrm{FeO}$ ion, which is known as Nanoscale zerovalent iron particles (nZVI), is massively used in the synthesis of nanoparticles applied in wastewater nano-based treatments. Bensaida et al. have shown that combining nZVI with another metal $(\mathrm{Cu})$ enhances the growth of the microbial populations in the wastewater treated with this nZVIICu bimetallic nanoparticles (Bensaida et al. 2021).

\section{Exploiting nanobiotechnology-based methods in food industry}

Nanotechnology-based pharmaceuticals were developed primarily, but wide applications of nanoscience in food and agricultural industries have been introduced as well (Sahani and Sharma 2020). Utilizing nanoscience in any stage of the food production process-either cultivation, production, post-harvest processing, or packaging-seems to be lucrative. The application of nano-based methods in the food industry has various advantages, but the most arguable of them would be its impact on shelf life augmentation and spoilage prevention (Bhuyan et al. 2019). Since Oxygen is known as an important cause of food spoilage in the food industry, scientists have developed the technology of advanced coatings based on nanotechnology to prevent Oxygen from spoiling the product (Rovera et al. 2020). Multiple nanoparticles have the potential to deliver nutritional or antimicrobial components into food materials (Bhuyan et al. 2019). It has been reported that nanotechnology is a good option to deliver pesticides and nutrients successfully into the soil and improve the strength and tolerance of products in different stressful situations and reduce the probable contaminations (Ali et al. 2021). Among different nanoparticles such as silver, titanium dioxide, and zinc oxide, nanoliposomes are found to be small and have a large surface area which makes them more adhesive to biological tissues- therefore more bioavailable in comparison to others. Nanoliposomes are suitable candidates for creating a delivery system during food preparation. Food provided with the help of nanotechnology is called "Nano food" (Bhuyan et al. 2019). Nano foods can perform as therapeutic options. It is interesting to mention a recent study that has proposed exploiting nanoemulsions to convey needed nutrients to gastrectomy patients. These types of patients usually suffer from conditions like anorexia, energy deficit, and malnutrition, which can be treated by efficient nutrition delivery provided by nano food (Razavi et al. 2020). As mentioned earlier, in the food preparation process, antimicrobial components can be delivered along with nutritional components via a nano-based delivery system. Polyphenols are great examples of substantial antioxidant and antimicrobial agents in the food industry. Nevertheless, polyphenols have some limitations, including instability, low solubility, inefficient bioavailability, and being drastically susceptible to being degraded. There are several factors that reinforce degradation: Oxygen, light, $\mathrm{pH}$, and interactions between polyphenols and other components in food. Polyphenolloaded nanoparticles relatively overcome the mentioned obstacles due to their capacity to protect phenolic compounds against degrading processes (Milinčić et al. 2019). As a renewable and biodegradable source, starch is a useful polymer that has been applied in different fields such as the pharmaceutical and food industries. Nano-size starch is an advanced material with new abilities in the matter of hydrophobicity and stability (Wang and Zhang 2020). In the field of the food industry, there are also many other new methods based on nanotechnology, for instance, designing natural proteins as nano-architectures to deliver nutraceuticals (Tang 2021), new strategies for packaging food products by exploitation of the knowledge of nano-biotechnology, and nanomaterials (Reshmy et al. 2021; Jogee et al. 2021; Tiwari et al. 2021), utilization of the nano-delivery techniques to overcome the problems of consuming bioactive ingredients (Hosseini et al. 2021; Ozogul et al. 2021), producing nanoparticles in the shape of powder using the nanospray driers (Jafari et al. 2021), 
detection of food contaminants by nano-Ag combinations (Yao et al. 2021), and even the application of nano-engineering in the field of the beverage industry (Saari and Chua 2020).

\section{Nano-bio catalysts; an attempt to remove the barriers of enzymatic bioprocesses in the biotechnology industry}

Organic enzymes, which are normally found in nature, have large applications in the biotechnology industry. Since organic enzymes are green and eco-friendly, they are usually preferred to commercially synthesized enzymes. Pectinase is considered to be extremely useful for manufacturing purposes. Pectinase application in industrial bioprocesses covers a large range from clarification of juice/ wine and tea/ coffee fermentation to wastewater and industrial waste remediation. All enzymes- regardless of being organic or chemically synthesized-consist of limitations that make their usage challenging. Three major disadvantages of enzymes are inefficient recoverability, operational stability, and recyclability (Zhang et al. 2021). Functional nanomaterial-based bio-carriers render a proper environment for the enzymatic immobilization process, therefore facilitating recovery and recycling of enzymes and enhancing the efficiency of bioprocesses in the long run. Accordingly, designing nanobased carriers with these features has been attracted great attention. To achieve this aim, Graphene- immobilized nanobio-catalysts have been proved to be greatly useful due to the Graphene's characteristics: electrical, optical, thermal, and mechanical high potency (Adeel et al. 2018; Zhang et al. 2021).

Nanomaterial-based nanocatalysts are useful in optimizing the biodiesel production process. This ability is related to the features of nano-scaled materials, including crystallisability, high adsorption and storage potential, having catalytic activities, and great stability and durability. Various materials can be used to create nanoparticles for this mean; some examples are metal oxide (calcium, magnesium oxide, and strontium oxide), Magnetic material, and Carbon. Carbon-based nanomaterials consist of multiple types, such as carbon nanotubes, carbon nanofibers, graphene oxide, and biochar.

All examples mentioned above have been proved to be highly effective in increasing the efficiency of the biodiesel synthesizing process and reducing the time and cost required for operating the process without utilizing nanotechnology (Nizami and Rehan 2018).

Replacing non-renewable energy sources with renewable ones is a great step in guaranteeing a sustainable future. Various devices, including solar and fuel cells, have been developed for this purpose. Conventional fuel cells are made from metal reactants instead of fossil fuels. They provide an electron circulation, transfer electrons from the substrate to specific electrodes, and eventually produce sustainable energy. The metals used as catalysts in fuel cells (e.g., hydrogen, methane, and methanol) are usually expensive and nondurable. On the other hand, biofuel cells use cost-effective bio-catalysts (e.g., microbes and enzymes) instead of metal catalysts. Despite the mentioned advantages, biofuel cells have one major limitation: the low rate of electron transfer between substrate and electrodes, which is significantly enhanced by supplementing biofuel cells with nanomaterials. Nanomaterials are able to assemble the substrate (e.g., enzymes) with the electrodes. In other words, using them in the structure of electrodes, the electron absorption of electrodes improves- related to the high surface area rate of nanomaterials- therefore, a direct transition of electrons between enzymes and electrodes develops. Silver nanoparticles-Graphene oxide (Ag-GO), Graphite, Carbon-nanotube forest (CNTF), Carbon nanotube (CNT), and Nitrogendoped hollow nanospheres with large pores (pNHCSs) are the nanomaterials applied in nano- biofuel cells. Respectively, Glucose oxidase $\left(\mathrm{GO}_{\mathrm{x}}\right)$, Glucose oxidase and Laccase, Fructose dehydrogenase \& laccase, Glucose oxidase and laccase, and NADH dehydrogenase form the enzymatic system of each nanomaterial (Sharma et al. 2021).

\section{Metal-organic frameworks (MOFs); highly advantageous materials}

Porous materials are known to be highly advantageous due to their high absorption and surface areas. Zeolites, activated carbons, and silicas are examples of this family, but the most eminent member among them are Metal-organic frameworks (MOFs). MOFs have features that make them unique for several applications. For example, MOFs show a high absorption rate, which is caused by their high surface areas. Another property of MOFs is their possession of several adjustable microporous channels, which makes it easy to produce different and changeable functional sites through them. The latest feature brings MOFs the shape and size selectivity. By controlling the starting materials and reaction parameters, it is possible to determine the morphology of MOFs (Kinik et al. 2020; Jun et al. 2020) into various shapes, including granule, pellet, thin-film, gel, foam, paper sheet, monolith, and hollow structures (Kinik et al. 2020).

There are two types of MOFs: (1) neutral MOFs and (2) ionic MOFs. Ionic MOFs are able to be used directly in anion purgation processes. For example, one approach for reducing the pollutant anions from the environment is synthesizing a cationic framework along with extra-framework anions. The synthesis of mentioned frameworks occurs by utilizing neutral nitrogen donors. The extra-framework anions will exchange with pollutant anions through an Ion exchange process called: "Anion trapping". 
Anions are extremely abundant in nature. One of the most pollutant and hazardous anions is phosphates. These toxic anions are highly used in pesticides. Other examples of toxic anions, which are considerably frequent in industrial wastes, are the bulky anions. These are the dye molecules exploited in industry. Various diseases like cancers, lung/kidney dysfunction, and brain diseases, including Alzheimer's, are caused by dangerous anions like those mentioned above. Hence, creating methods that are able to recognize and delete the perilous anions from the environment is one of the most appreciated scientific approaches. MOFs have been proved to be functional for this mean (Desai et al. 2019).

Since MOFs have considerable surface areas and modifiable structure-different open metal sites and other functional groups can be introduced into their frameworks - they are suitable options for numerous applications which are generally related to detection and storage. In the case of storage, they exhibit acceptable physical adsorption for $\mathrm{CO}_{2}$ (one of the major causes of global warming), $\mathrm{H}_{2}$ (a clean energy source), and Methane $\left(\mathrm{CH}_{4}\right)$. The ability to adsorb variant components makes MOFs proper for water purification applications. Several toxic and harmful components which are responsible for water contamination, including organic pollutants (like dyes and oils) and heavy metal ions, can be detected, adsorbed, and removed by MOFs. Introducing different chemical groups into MOFs creates different internal interactions, which enable MOFs to detect target molecules functionally. Therefore, they can be used in active centers of catalysts, photocatalysts, and biosensors (Kinik et al. 2020).

\section{MOFs-based nanozymes}

Nanozymes are classified into two types: (1) natural enzymes that are incorporated with nanomaterials and (2) nanomaterials that exhibit inherent enzymatic features. Exploiting MOFs as nanomaterials in nanozyme structures will produce an emergent form of nanozymes, called: "MOF-based nanozymes"; which have multiple advantages over conventional forms. MOFs provide more catalytic sites, simplify the entrance of small substrate molecules -due to their porous structure-, enhance the substrate exclusivity, and altogether improve the catalytic function of enzymes. MOF-based nanozymes are effective in designing biosensors, biocatalysis, and biomedical imaging techniques. A recent promising application of them is in cancer therapy which reduces side effects significantly (Ding et al. 2020).

\section{Agricultural usages of nanobiotechnology}

Applying nanobiotechnology in agriculture to improve the agricultural production rate has been of great importance recently. Achieving this purpose will solve several problems related to the universal hunger dilemma. Several nanofertilizers, nano pesticides, and nano-bio sensors have been created, which are able to increase crop value and decrease crop loss caused by agricultural pests (Usman et al. 2020). Conventional chemical pesticides and fertilizers can be deteriorative for soil composition and fertility. This happens because chemical residues can target many molecules other than the ones that have been defined as their main targets (Chhipa 2019). Besides, pesticides can have ruinous impacts on the microorganisms that naturally exist in the environment and are required for the crop's growth (Nehra et al. 2021). Utilizing nanoparticles can considerably reduce such unwanted events due to the high exclusivity of these particles. Silver, zinc, iron, titanium, phosphorus, molybdenum, and polymer are suitable materials to be used in the structure of agricultural nanoparticles (Chhipa 2019). Nanoparticles containing nutrients, fertilizers, and pesticides, can be sprayed externally to the plant. The folium will adsorb the nanoparticles and send them to the soil (Chugh et al. 2021).

Another application of nanobiotechnology in diminishing the damages of some traditional pesticides is designing nano-bio sensors that can efficiently detect toxic pesticides. Dichlorvos is one of these toxic pesticides that accumulate in the air, soil, water, and crops; and therefore causes neural, genetical, respirational, and muscular disorders. Dichlorvos-sensitive Nano-biosensors comprise immobilized enzymes embedded in nanomaterials. Acetylcholinesterase (AChE), tyrosinase enzymes, and some others are options for the enzymatic part of the nanodevice. For the nano- matrix section, both organic (carbon, graphene, chitosan, and onion membrane) and inorganic (silver, gold, silica, and Titania) options are available (Mishra et al. 2021). Nanomaterials can enhance the remediation process of contaminated soils through distinct abiotic and biotic directions, including the nano-bioremediation process (Usman et al. 2020).

Other than improving the functions of existed plants, the possibility of introducing engineered plants with better performances has been discussed recently. The term "plant nano bionics" refers to a pioneering idea of involving nanoparticles in living plants to make their intrinsic functions adjustable. The landscape of this idea is designing engineered artificial photosynthetic systems, enhancing the growth rate of this new type of plant, and many other novel applications which are expected to grow extremely in the years ahead (Marchiol 2018).

It is necessary to mention that inorganic nanoparticles that may be found in consumer products, may alter the gut composition and could lead to various gut-related diseases. Thus, there have to be some limitations in nanoparticle agricultural usages (Gangadoo et al. 2021; Ghebretatios et al. 2021). 


\section{Using nanoparticles in cosmetic products}

Nowadays, due to special and distinctive physicochemical characteristics, nanomaterials are being vastly used in different industries. Recent studies are focused on applying nano-based technologies to improve the quality of cosmetic products. Nanostructures are about to deliver active ingredients to the skin. For this reason, it is more suitable to use lipid particles that are better adaptable to dermal absorption. The high stability of the combination of nanomaterials and lipid particles with cosmetic components indicates high efficiency. However, the probable risks of this method should not be ignored (Benrabah et al. 2020; Khezri et al. 2018). Producing nanoparticles using plants (Phyto-metal nano-based particles) is another advantageous method to decrease the toxicity of nanomaterials and their hazardous effects on the body. For this reason, this material is suitable for dermal uses and cosmetic applications (Paiva-Santos et al. 2021). Chitosan nanoparticles with better penetrability (Ta et al. 2021; Sakulwech et al. 2018), Gold and silver nanoparticles with a higher ability to reduce microbial contaminants (Séby 2021), Titanium dioxide $\left(\mathrm{TiO}_{2}\right)$ nanoparticles deposited with yttrium oxide $\left(\mathrm{Y}_{2} \mathrm{O}_{3}\right)$ with better attenuation of ultraviolet radiation and less cytotoxicity (Borrás et al. 2020), nanoparticles with high uptake of oily components (de Azevedo Stavale et al. 2019) are other examples of the efficient application of nanotechnology in the field of cosmetic products.

Since nanoparticles are small in size, they exhibit perfect penetrability through the skin. Hence, using nanoparticles in cosmetic productions improves the supplementation of skin, hair, or teeth with active cosmetic ingredients (APIs). It is important to note that utilizing nanoparticles for several applications, as an emerging field of science, causes various concerns about being toxic or harmful for the body or the environment. The cosmetic industry's products are commonly designed for skin, hair, nail, teeth, and therefore, are directly related to the health of the human body. Thus, it is reasonable to assume that there are even more concerns about using nanoparticles in this industry compared to others (Santos et al. 2019).

In addition to these cases, nanotechnology can be useful for the detection of harmful components in cosmetic ingredients. Therefore the application of methods like covered iron oxide nanoparticles with silver for detection of mercury contamination in cosmetics (Chen et al. 2021a, b), Quantitative assessment of the Triamcinolone acetonide (TCA) (which is a hazardous component in high doses) using nanoparticles with luminescence property (Zhang et al. 2019a), And detection of harmful N-nitrosamines with the utilization of magnetic nanoparticles (Miralles et al. 2019) are worth mentioning.

\section{Oil industry benefits from multiple types of nanomaterials}

Nanomaterials can play a major role in the advancement of the oil industry. Almost every form of nanomaterialdiscussed in previous sections - has been exhibited to have numerous applications in the oil industry. Nanomaterial can be effectively exploited in various processes of this industry, including oil exploration/production and recovering the oilfield. Nanofluids (synthesized from nanomaterials) optimize the oil production process. Nanocatalysts have applications in petrochemical processes along with operating an efficient oil purgation function. Several applications of this technology are mentioned below.

There are nanomembranes designed to provide a proper matrix for separating water and oil from gas. They eventually purify the gas and delete redundant components from wastewater (Saleh 2018). Metal workings such as machining and stamping industry require some types of lubricants and coolants, which are mostly oil products. There has been produced an oil-based cutting fluid made up of $\mathrm{Al}_{2} \mathrm{O}_{3}$ nanoparticles to decrease the friction force between the object and snipping tool (Subhedar et al. 2021). Encapsulation of extracted essential oil from hyssop in a nano-complex improves the antioxidant and antifungal efficiency of the oil (Hadidi et al. 2021). The application of nano-silica in the procedure of oil cementing enhances the resistance of the cement (Goyal et al. 2021; Thakkar et al. 2020). In the process of oil recovery, there is a high energy loss that imposes damages to the injection system and lowers the heat level. To keep the rate of temperature in a higher range and decrease the energy loss, scientists have applied nano-thermal insulators that are more economical (Afra et al. 2021; Zhao et al. 2021; Zhou et al. 2020). Gas and oil products can be cleaned from $\mathrm{H}_{2} \mathrm{~S}$ by applying nanomaterials (Agarwal and Sudharsan 2021). Utilizing starch nano coatings (Wang et al. 2021), Lignin and nano-silica (Gong et al. 2021), Lotus leaf coated with nano- $\mathrm{SiO}_{2}$ (Yang et al. 2021), and nano zeolite membrane are new methods for the separation of oil and water due to their high hydrophobic property (Anis et al. 2021). Nanotechnology can be used to improve the quality of engine oil, which results in the better stability and lubricity power as well as a reduced rate of released carbon mono oxide (Tonk 2021; Saidi et al. 2021; Thirugnanam et al. 2021; Ardebili et al. 2020). Advanced nanoemulsions show high stability and benefits for the oil industry due to the larger surface and the ability to wet (Kumar et al. 2021). Encapsulation of essential oils in nanostructures indicates a better performance as a pesticide due to better maintenance of the oil (Campolo et al. 2020). Producing an oil-in-water emulsion by applying protein nanoparticles can protect unstable and active ingredients and benefit the medicine and food industry (Xu et al. 2020). 


\section{Conclusion}

Combining diverse fields of science in a manner that they overcome each other's deficiencies indicates promising results. Within the last decades, biotechnology has made a lot of progress. Merging nanotechnology with biotechnological methods enables scientists to design less time taking, more economical, and more efficient techniques. This Nano-biotechnological approach influences multiple therapeutic, agricultural, environmental, and industrial methods. For instance, the effectiveness of the emergent crisper/cas 9 systems increases noticeably by applying the nano-scaled additives at the process.

In this review, we investigated the current advancements and limitations of biotechnology, along with the nano-based alternatives rendered by nanotechnology. It seems highly probable that biotechnology will accomplish even more improvements in the future, and its incorporation with nanotechnology gets humankind one step closer to a sustainable future. Besides, the nano-based techniques are less costly compared to the conventional ones. Thus, with nano-biotechnology promoting, a revolution in the economic situation of the world is not implausible.

Author contributions All authors have participated in (a) conception and design, or analysis and interpretation of the data; (b) drafting the article or revising it critically for important intellectual content; and (c) approval of the final version. This manuscript has not been submitted to, nor is under review at, another journal or other publishing venue. The authors have no affiliation with any organization with a direct or indirect financial interest in the subject matter discussed in the manuscript.

\section{Declarations}

Conflict of interest On behalf of all authors, the corresponding author states that there is no conflict of interest.

\section{References}

Abass OK, Zhang K (2020) Nano-Fe mediated treatment of real hydraulic fracturing flowback and its practical implication on membrane fouling in tandem anaerobic-oxic membrane bioreactor. J Hazard Mater 395:122666

Abdelhamid HN, Badr G (2021) Nanobiotechnology as a platform for the diagnosis of COVID-19: a review. Nanotechnol Environ Eng 6(1):1-26

Adam H, Youssef A (2019) Economic impacts of nanotechnology industry: case study on Egypt. In: Proceedings of 10th International Conference on Digital Strategies for Organizational Success. https://doi.org/10.2139/ssrn.3314931

Adeel M, Bilal M, Rasheed T, Sharma A, Iqbal HMN (2018) Graphene and graphene oxide: functionalization and nano-bio-catalytic system for enzyme immobilization and biotechnological perspective. Int J Biol Macromol 120(Pt B):1430-1440
Afra M, Peyghambarzadeh SM, Shahbazi K, Tahmassebi N (2021) Thermo-economic optimization of steam injection operation in enhanced oil recovery (EOR) using nano-thermal insulation. Energy 226:120409

Agarwal M, Sudharsan J (2021) A comprehensive review on scavenging $\mathrm{H}_{2} \mathrm{~S}$ compounds in oil and gas industry by using nanomaterials. Mater Today Proc. https://doi.org/10.1016/j.matpr.2020. 11.693

Ahire JJ, Dicks LMT (2014) 2,3-dihydroxybenzoic acid-containing nanofiber wound dressings inhibit biofilm formation by Pseudomonas aeruginosa. Antimicrob Agents Chemother 58(4):2098-2104

Ahire JJ, Dicks LM (2016) Antimicrobial hyaluronic acid-cefoxitin sodium thin films produced by electrospraying. Curr Microbiol 73(2):236-241

Ahire JJ, Neveling DP (2018) Dicks LM (2018) Polyacrylonitrile (PAN) nanofibres spun with copper nanoparticles: an antiEscherichia coli membrane for water treatment. Appl Microbiol Biotechnol 102(16):7171-7181

Ahire JJ, Hattingh M, Neveling DP, Dicks LM (2016) Copper-containing anti-biofilm nanofiber scaffolds as a wound dressing material. PLoS ONE 11(3):e0152755

Ahire JJ, Robertson DD, van Reenen AJ, Dicks LMT (2017a) Polyethylene oxide (PEO)-hyaluronic acid (HA) nanofibers with kanamycin inhibits the growth of Listeria monocytogenes. Biomed Pharmacother 86:143-148

Ahire JJ, Robertson DD, Van Reenen AJ, Dicks LM (2017b) Surfactin-loaded polyvinyl alcohol (PVA) nanofibers alters adhesion of Listeria monocytogenes to polystyrene. Mater Sci Eng C 77:27-33

Ahmadi MH, Ghazvini M, Alhuyi Nazari M, Ahmadi MA, Pourfayaz F, Lorenzini G, Ming T (2019) Renewable energy harvesting with the application of nanotechnology: a review. Int J Energy Res 43(4):1387-1410

Al-Attabi R, Rodriguez-Andres J, Schütz JA, Bechelany M, Des Ligneris E, Chen X, Kong L, Morsi YS, Dumee LF (2019) Catalytic electrospun nano-composite membranes for virus capture and remediation. Sep Purif Technol 229:115806

Al-Gheethi AAS, Mohamed RMSR, Noman EA, Kassim AHM (eds) (2020) Prospects of fresh market wastes management in developing countries. Water science and technology library, vol 92. Springer, Cham

Ali M, Hoque M, Safdar Hossain S, Biswas M (2020) Nanoadsorbents for wastewater treatment: next generation biotechnological solution. Int J Environ Sci Technol 17:4095-4132

Ali SS, Al-Tohamy R, Koutra E, Moawad MS, Kornaros M, Mustafa AM, Mahmoud YA-G, Badr A, Osman ME, Elsamahy T (2021) Nanobiotechnological advancements in agriculture and food industry: applications, nanotoxicity, and future perspectives. Sci Total Environ 792:148359

AlNadhari S, Al-Enazi NM, Alshehrei F, Ameen F (2021) A review on biogenic synthesis of metal nanoparticles using marine algae and its applications. Environ Res 194:110672

Anis SF, Lalia BS, Lesimple A, Hashaikeh R, Hilal N (2021) Superhydrophilic and underwater superoleophobic nano zeolite membranes for efficient oil-in-water nanoemulsion separation. J Water Process Eng 40:101802

Ardebili SMS, Taghipoor A, Solmaz H, Mostafaei M (2020) The effect of nano-biochar on the performance and emissions of a diesel engine fueled with fusel oil-diesel fuel. Fuel 268:117356

Ashraf S, Siddiqa A, Shahida S, Qaisar S (2019) Titanium-based nanocomposite materials for arsenic removal from water: a review. Heliyon 5(5):e01577

Azarakhsh F, Divsalar A, Saboury AA, Eidi A (2021) Simultaneous Delivery of Oxali-palladium and Iron Nanoparticles by $\beta$-Casein. Journal of Molecular Liquids:115999

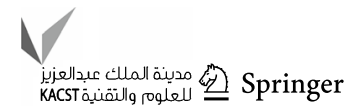


Azeez NA, Dash SS, Gummadi SN, Deepa VS (2020) Nano-remediation of toxic heavy metal contamination: Hexavalent chromium [Cr (VI)]. Chemosphere: 129204

Banerjee S, Dubey S, Gautam RK, Chattopadhyaya M, Sharma YC (2019) Adsorption characteristics of alumina nanoparticles for the removal of hazardous dye, Orange $\mathrm{G}$ from aqueous solutions. Arab J Chem 12(8):5339-5354

Barani M, Bilal M, Sabir F, Rahdar A, Kyzas GZ (2021) Nanotechnology in ovarian cancer: diagnosis and treatment. Life Sci 266:118914

Bashir F, Irfan M, Ahmad T, Iqbal J, Butt MT, Sadef Y, Umbreen M, Shaikh IA, Moniruzzaman M (2021) Efficient utilization of low cost agro materials for incorporation of copper nanoparticles to scrutinize their antibacterial properties in drinking water. Environ Technol Innov 21:101228

Bayda S, Adeel M, Tuccinardi T, Cordani M, Rizzolio F (2020) The history of nanoscience and nanotechnology: from chemicalphysical applications to nanomedicine. Molecules 25(1):112

Benrabah L, Kemel K, Twarog C, Huang N, Solgadi A, Laugel C, Faivre V (2020) Lipid-based Janus nanoparticles for pharmaceutical and cosmetic applications: kinetics and mechanisms of destabilization with time and temperature. Colloids Surfaces B 195:111242

Bensaida K, Eljamal R, Sughihara Y, Eljamal O (2021) The impact of iron bimetallic nanoparticles on bulk microbial growth in wastewater. J Water Process Eng 40:101825

Beryani A, Pardakhti A, Ardestani M, Zahed MA (2017) Benzene and MTBE removal by Fenton's process using stabilized Nano Zero-Valent Iron particles. J Appl Res Water Wastewater 4(2):343-348. https://doi.org/10.22126/arww.2017.788

Bhuyan D, Greene GW, Das RK (2019) Prospects and application of nanobiotechnology in food preservation: molecular perspectives. Crit Rev Biotechnol 39(6):759-778

Biesiada M, Pachulska-Wieczorek K, Adamiak RW, Purzycka KJ (2016) RNAComposer and RNA 3D structure prediction for nanotechnology. Methods 103:120-127

Borrás MC, Sluyter R, Barker PJ, Konstantinov K, Bakand S (2020) Y2O3 decorated TiO2 nanoparticles: enhanced UV attenuation and suppressed photocatalytic activity with promise for cosmetic and sunscreen applications. J Photochem Photobiol B Biol 207:111883

Campolo O, Giunti G, Laigle M, Michel T, Palmeri V (2020) Essential oil-based nano-emulsions: effect of different surfactants, sonication and plant species on physicochemical characteristics. Ind Crops Prod 157:112935

Cardoso VF, Francesko A, Ribeiro C, Bañobre-López M, Martins $\mathrm{P}$, Lanceros-Mendez S (2018) Advances in magnetic nanoparticles for biomedical applications. Adv Healthcare Mater 7(5): 1700845

Chai JM, Amelia TSM, Mouriya GK, Bhubalan K, Amirul A-AA, Vigneswari S, Ramakrishna S (2021) Surface-Modified highly biocompatible bacterial-poly (3-hydroxybutyrate-co-4-hydroxybutyrate): a review on the promising next-generation biomaterial. Polymers 13(1):51

Chen H, Gu L, Liao B, Zhou X, Cheng L, Ren B (2020) Advances of anti-caries nanomaterials. Molecules 25(21):5047

Chen L, Ai J, Cai H, Chen X, Liu Z, Li Z, Dai F (2021a) Antibacterial gauze based on the synergistic antibacterial mechanism of antimicrobial peptides and silver nanoparticles. J Polym Res 28(2):1-9

Chen Z-Y, Gupta A, Chattopadhyay S (2021b) Detection of mercury in spiked cosmetics by surface enhanced Raman spectroscopy using silver shelled iron oxide nanoparticles. Sens Actuators B Chem 337:129788

Chhipa H (2019) Applications of nanotechnology in agriculture. Methods Microbiol 46:115-142
Chiari-Andréo BG, Almeida-Cincotto MGJd, Oshiro JA, Taniguchi CYY, Chiavacci LA, Isaac VLB (2019) Chapter 5-Nanoparticles for cosmetic use and its application. In: Grumezescu AM (ed) Nanoparticles in pharmacotherapy. William Andrew Publishing, pp 113-146

Chugh G, Siddique KH, Solaiman ZM (2021) Nanobiotechnology for agriculture: smart technology for combating nutrient deficiencies with nanotoxicity challenges. Sustainability 13(4):1781

Costa JSD, Hoskisson PA, Paterlini P, Romero CM, Alvarez A (2020) Whole genome sequence of the multi-resistant plant growthpromoting bacteria Streptomyces sp. Z38 with potential application in agroindustry and bio-nanotechnology. Genomics 112(6):4684-4689

D’Acunto M, Cioni P, Gabellieri E, Presciuttini G (2021) Exploiting gold nanoparticles for diagnosis and cancer treatments. Nanotechnology 32(19):192001

de Azevedo Stavale A, Fonseca GO, Duarte PS, Macedo LC, Percebom AM (2019) Nanoparticles of surfactant and block copolymers with high uptake of oily ingredients for cosmetic formulations. Colloids Surf A Physicochem Eng Asp 581:123779

De Luca I, Pedram P, Moeini A, Cerruti P, Peluso G, Di Salle A, Germann N (2021) Nanotechnology development for formulating essential oils in wound dressing materials to promote the woundhealing process: a review. Appl Sci 11(4):1713

Debnath M, Chauhan N, Sharma P, Tomar I (2021) Potential of nano biosurfactants as an ecofriendly green technology for bioremediation. Handbook of nanomaterials for wastewater treatment. Elsevier, pp 1039-1055

Deng H, Huang W, Zhang Z (2019) Nanotechnology based CRISPR/ Cas9 system delivery for genome editing: progress and prospect. Nano Res 12(10):2437-2450

Desai AV, Sharma S, Ghosh SK (2019) Metal-organic frameworks for recognition and sequestration of toxic anionic pollutants. Metalorganic frameworks (MOFs) for environmental applications. Elsevier, pp 95-140

Ding S-s, He L, Bian X-w, Tian G (2020) Metal-organic frameworksbased nanozymes for combined cancer therapy. Nano Today 35:100920

Doroudian M, MacLoughlin R, Poynton F, Prina-Mello A, Donnelly SC (2019) Nanotechnology based therapeutics for lung disease. Thorax 74(10):965-976

Doroudian M, O'Neill A, Mac Loughlin R, Prina-Mello A, Volkov Y, Donnelly SC (2021) Nanotechnology in pulmonary medicine. Curr Opin Pharmacol 56:85-92

Du T, Zhang J, Li C, Song T, Li P, Liu J, Du X, Wang S (2020) Gold/ silver hybrid nanoparticles with enduring inhibition of coronavirus multiplication through multisite mechanisms. Bioconjug Chem 31(11):2553-2563

Ebrahimbabaie P, Meeinkuirt W, Pichtel J (2020) Phytoremediation of engineered nanoparticles using aquatic plants: mechanisms and practical feasibility. J Environ Sci 93:151-163

Evelyn Roopngam P (2019) Liposome and polymer-based nanomaterials for vaccine applications. Nanomed J 6(1):1-10

Farrera C, Torres Andón F, Feliu N (2017) Carbon nanotubes as optical sensors in biomedicine. ACS Nano 11(11):10637-10643

Fidoski J, Benedetti A, Kirkov A, Iliev A, Stamatoski A, Baftijari D (2020) Nano-emulsion complex (propolis and vitamin C) promotes wound healing in the oral mucosa. Oral Maxillofac Patho J 11(1):1-5

Fouad GI (2021) A proposed insight into the anti-viral potential of metallic nanoparticles against novel coronavirus disease-19 (COVID-19). Bull Natl Res Cent 45(1):1-22

Furtado D, Björnmalm M, Ayton S, Bush AI, Kempe K, Caruso F (2018) Overcoming the blood-brain barrier: the role of nanomaterials in treating neurological diseases. Adv Mater 30(46):1801362 
Gangadoo S, Nguyen H, Rajapaksha P, Zreiqat H, Latham K, Cozzolino D, Truong VK (2021) Inorganic nanoparticles as food additives and their influence on the human gut microbiota. Environ Sci Nano 8:1500-1518

Ghebretatios M, Schaly S, Prakash S (2021) Nanoparticles in the food industry and their impact on human gut microbiome and diseases. Int J Mol Sci 22(4):1942

Gökçe D (2021) Influences of nanoparticles on aquatic organisms: current situation of nanoparticles effects in aquatic ecosystems. Sust Eng Innov 3(1):54-60

Gong X, Meng Y, Zhu J, Wang X, Lu J, Cheng Y, Tao Y, Wang H (2021) Construct a stable super-hydrophobic surface through acetonitrile extracted lignin and nano-silica and its application in oil-water separation. Ind Crops Prod 166:113471

González-Ballesteros N, Prado-López S, Rodríguez-González J, Lastra M, Rodríguez-Argüelles M (2017) Green synthesis of gold nanoparticles using brown algae Cystoseira baccata: Its activity in colon cancer cells. Colloids Surf B 153:190-198

Goracci M, Pignochino Y, Marchiò S (2020) Phage display-based nanotechnology applications in cancer immunotherapy. Molecules 25(4):843

Goyal S, Joshi P, Singh R (2021) Applications and role of NanoSilica particles on altering the properties and their usage for oil well cementing. Mater Today Proc 46:10681-10686

Hadidi M, Motamedzadegan A, Jelyani AZ, Khashadeh S (2021) Nanoencapsulation of hyssop essential oil in chitosan-pea protein isolate nano-complex. LWT 144:111254

Hager S, Fittler FJ, Wagner E, Bros M (2020) Nucleic acid-based approaches for tumor therapy. Cells 9(9):2061

Hajiabadi SH, Aghaei H, Kalateh-Aghamohammadi M, Shorgasthi M (2020) An overview on the significance of carbon-based nanomaterials in upstream oil and gas industry. J Pet Sci Eng 186:106783

He Y, Lin H, Luo M, Liu J, Dong Y, Li B (2020) Highly efficient remediation of groundwater co-contaminated with $\mathrm{Cr}(\mathrm{VI})$ and nitrate by using nano-Fe/Pd bimetal-loaded zeolite: process product and interaction mechanism. Environ Pollut 263:114479

Hosseini SF, Ramezanzade L, McClements DJ (2021) Recent advances in nanoencapsulation of hydrophobic marine bioactives: bioavailability, safety, and sensory attributes of nano-fortified functional foods. Trends Food Sci Technol 109:322-339

Hou S, Wu B, Peng D, Wang Z, Wang Y, Xu H (2019) Remediation performance and mechanism of hexavalent chromium in alkaline soil using multi-layer loaded nano-zero-valent iron. Environ Pollut 252:553-561

Islam MA, Rice J, Reesor E, Zope H, Tao W, Lim M, Ding J, Chen Y, Aduluso D, Zetter BR (2021) Adjuvant-pulsed mRNA vaccine nanoparticle for immunoprophylactic and therapeutic tumor suppression in mice. Biomaterials 266:120431

Iwaniec DM, Cook EM, Davidson MJ, Berbés-Blázquez M, Georgescu M, Krayenhoff ES, Middel A, Sampson DA, Grimm NB (2020) The co-production of sustainable future scenarios. Landsc Urban Plan 197:103744

Jafari SM, Arpagaus C, Cerqueira MA, Samborska K (2021) Nano spray drying of food ingredients; materials, processing and applications. Trends Food Sci Technol 109:632-646

Jang W, Kwon H, Park Y, Lee H (2018) Predicting the degree of interdisciplinarity in academic fields: the case of nanotechnology. Scientometrics 116(1):231-254

Jeevanandam J, Pal K, Danquah MK (2019) Virus-like nanoparticles as a novel delivery tool in gene therapy. Biochimie 157:38-47

Jeong YJ, Kim DS, Kim JY, Oyunbaatar NE, Shanmugasundaram A, Kim ES, Lee DW (2021) On-stage bioreactor platform integrated with nano-patterned and gold-coated PDMS diaphragm for live cell stimulation and imaging. Mater Sci Eng C-Mater Biol Appl 118:9. https://doi.org/10.1016/j.msec.2020.111355
Jiang Y, Khan A, Huang H, Tian Y, Yu X, Xu Q, Mou L, Lv J, Zhang P, Liu P, Deng L, Li X (2019) Using nano-attapulgite clay compounded hydrophilic urethane foams (AT/HUFs) as biofilm support enhances oil-refinery wastewater treatment in a biofilm membrane bioreactor. Sci Total Environ 646:606-617

Jogee P, Agarkar G, Rai M (2021) Starch-based films loaded with nanoantimicrobials for food packaging. Biopolymer-based nano films. Elsevier, pp 99-114

Jun B-M, Al-Hamadani YA, Son A, Park CM, Jang M, Jang A, Kim NC, Yoon Y (2020) Applications of metal-organic framework based membranes in water purification: a review. Sep Purif Technol 247:116947

Kailasa SK, Mehta VN, Koduru JR, Basu H, Singhal RK, Murthy Z, Park T-J (2021) An overview of molecular biology and nanotechnology based analytical methods for the detection of SARSCoV-2: promising biotools for the rapid diagnosis of COVID-19. Analyst 146(5):1489-1513

Karimzadeh Z, Javanbakht S, Namazi H (2019) Carboxymethylcellulose/MOF-5/Graphene oxide bio-nanocomposite as antibacterial drug nanocarrier agent. BioImpacts 9(1):5

Ken DS, Sinha A (2020) Recent developments in surface modification of nano zero-valent iron (nZVI): remediation, toxicity and environmental impacts. Environ Nanotechnol Monit Manag 24:100344

Khezri K, Saeedi M, Dizaj SM (2018) Application of nanoparticles in percutaneous delivery of active ingredients in cosmetic preparations. Biomed Pharmacother 106:1499-1505

Kim S, Kim K, Jun G, Hwang W (2020) Wood-nanotechnology-based membrane for the efficient purification of oil-in-water emulsions. ACS Nano 14(12):17233-17240

Kinik FP, Kampouri S, Ebrahim FM, Valizadeh B, Stylianou KC (2020) Porous metal-organic frameworks for advanced applications. Elsevier

Kinloch IA, Suhr J, Lou J, Young RJ, Ajayan PM (2018) Composites with carbon nanotubes and graphene: an outlook. Science 362(6414):547-553

Korde JM, Kandasubramanian B (2020) Microbiologically extracted poly (hydroxyalkanoates) and its amalgams as therapeutic nanocarriers in anti-tumor therapies. Mater Sci Eng C 111:110799

Kumar S, Kashyap PL, Mahapatra S, Jasrotia P, Singh GP (2020) New and emerging technologies for detecting Magnaporthe oryzae causing blast disease in crop plants. Crop Prot 143:105473

Kumar N, Verma A, Mandal A (2021) Formation, characteristics and oil industry applications of nanoemulsions: a review. J Pet Sci Eng 206:109042

Kutara BMRNS, Sutharb H, Mohitec KC, Devid R (2016) Bioinformatics, biotechnology and nanotechnology tools for environment engineering: way to sustainable development by wastewater treatment

Landowski LM, Niego B, Sutherland BA, Hagemeyer CE, Howells DW (2020) Applications of nanotechnology in the diagnosis and therapy of stroke. Semin Thromb Hemost 46(5):592-605. https:// doi.org/10.1055/s-0039-3399568

Le TT, Yoon H, Son M-H, Kang Y-G, Chang Y-S (2019) Treatability of hexabromocyclododecane using $\mathrm{Pd} / \mathrm{Fe}$ nanoparticles in the soil-plant system: effects of humic acids. Sci Total Environ 689:444-450

Lew TTS, Koman VB, Gordiichuk P, Park M, Strano MS (2020) The emergence of plant nanobionics and living plants as technology. Adv Mater Technol 5(3): 1900657

Li T, Fang F, Yang Y, Shen W, Bao W, Zhang T, Ai F, Ding X, Xin H, Wang X (2019) Surface nano-engineered wheat straw for portable and adjustable water purification. Sci Total Environ 655:1028-1036

Li R, Ng TS, Wang SJ, Prytyskach M, Rodell CB, Mikula H, Kohler RH, Garlin MA, Lauffenburger DA, Parangi S (2021)

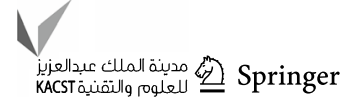


Therapeutically reprogrammed nutrient signalling enhances nanoparticulate albumin bound drug uptake and efficacy in KRAS-mutant cancer. Nat Nanotechnol. https://doi.org/10. 1038/s41565-021-00897-1

Lian M, Wang L, Feng Q, Niu L, Zhao Z, Wang P, Song C, Li X, Zhang Z (2021) Thiol-functionalized nano-silica for in-situ remediation of $\mathrm{Pb}, \mathrm{Cd}, \mathrm{Cu}$ contaminated soils and improving soil environment. Environ Pollut 280:116879

Lim M, Badruddoza AZM, Firdous J, Azad M, Mannan A, Al-Hilal TA, Cho C-S, Islam MA (2020) Engineered nanodelivery systems to improve DNA vaccine technologies. Pharmaceutics 12(1):30

Lin Y-X, Wang Y, Blake S, Yu M, Mei L, Wang H, Shi J (2020) RNA nanotechnology-mediated cancer immunotherapy. Theranostics 10(1):281-299. https://doi.org/10.7150/thno.35568

Lincy A, Jegathambal P, Mkandawire M, MacQuarrie S (2020) Nano bioremediation of textile dye effluent using magnetite nanoparticles encapsulated alginate beads. J Environ Treat Tech 8(3):936-946

Liu B, Hu F, Zhang JF, Wang CL, Li LL (2019) A biomimetic coordination nanoplatform for controlled encapsulation and delivery of drug-gene combinations. Angew Chem-Int Edit 58(26):8804-8808

Lohrasebi A, Koslowski T (2019) Modeling water purification by an aquaporin-inspired graphene-based nano-channel. J Mol Model 25(9):280

Lombardo D, Kiselev MA, Caccamo MT (2019) Smart nanoparticles for drug delivery application: development of versatile nanocarrier platforms in biotechnology and nanomedicine. $\mathrm{J}$ Nanomater. https://doi.org/10.1155/2019/3702518

Luo Y, Wang Q, Zhang Y (2020) Biopolymer-based nanotechnology approaches to deliver bioactive compounds for food applications: a perspective on the past, present, and future. J Agric Food Chem 68(46):12993-13000

Luo Z, Zhu J, Yu L, Yin K (2021) Heavy metal remediation by nano zero-valent iron in the presence of microplastics in groundwater: inhibition and induced promotion on aging effects. Environ Pollut 287:117628

Lyu P, Javidi-Parsijani P, Atala A, Lu B (2019) Delivering Cas9/ sgRNA ribonucleoprotein (RNP) by lentiviral capsid-based bionanoparticles for efficient 'hit-and-run'genome editing. Nucleic Acids Res 47(17):e99-e99

Ma J, Dai R, Chen M, Khan SJ, Wang Z (2018) Applications of membrane bioreactors for water reclamation: micropollutant removal, mechanisms and perspectives. Biores Technol 269:532-543

Mahmoud ME, Allam EA, El-Sharkawy RM, Soliman MA, Saad EA, El-Khatib AM (2020) Nano-manganese oxide-functionalizedoleyl amine as a simple and low cost nanosorbent for remediation of $\mathrm{ZnII} / \mathrm{CoII}$ and their radioactive nuclides $65 \mathrm{Zn}$ and $60 \mathrm{Co}$ from water. Appl Radiat Isot 159:108989

Maine E, Thomas V, Bliemel M, Murira A, Utterback J (2014) The emergence of the nanobiotechnology industry. Nat Nanotechnol 9(1):2-5

Majhi RK, Mohanty S, Khan MI, Mishra A, Brauner A (2021) Ag@ $\mathrm{ZnO}$ nanoparticles induce antimicrobial peptides and promote migration and antibacterial activity of keratinocytes. ACS Infect Dis. https://doi.org/10.1021/acsinfecdis.0c00903

Malik SN, Khan SM, Ghosh PC, Vaidya AN, Kanade G, Mudliar SN (2019) Treatment of pharmaceutical industrial wastewater by nano-catalyzed ozonation in a semi-batch reactor for improved biodegradability. Sci Total Environ 678:114-122

Manikanika KJ, Jaswal S (2021) Role of nanotechnology in the world of cosmetology: a review. Mater Today Proc. https://doi.org/ 10.1016/j.matpr.2020.12.638
Mantatov V, Mantatova L, Nasibulina A, Tutubalin V (2019) The conception of sustainable development in the light of converging technologies. Eur Asian J Bio Sci 13(2):2159-2165

Marchiol L (2018) Nanotechnology in agriculture: new opportunities and perspectives. New Visions Plant Sci 9(4):161

Marcos-Contreras OA, Greineder CF, Kiseleva RY, Parhiz H, Walsh LR, Zuluaga-Ramirez V, Myerson JW, Hood ED, Villa CH, Tombacz I, Pardi N, Seliga A, Mui BL, Tam YK, Glassman PM, Shuvaev VV, Nong J, Brenner JS, Khoshnejad M, Madden T, Weissmann D, Persidsky Y, Muzykantov VR (2020) Selective targeting of nanomedicine to inflamed cerebral vasculature to enhance the blood-brain barrier. Proc Natl Acad Sci 117(7):3405-3414

Meikle TG, Dharmadana D, Hoffmann SV, Jones NC, Drummond CJ, Conn CE (2021) Analysis of the structure, loading and activity of six antimicrobial peptides encapsulated in cubic phase lipid nanoparticles. J Colloid Interface Sci 587:90-100

Milinčić DD, Popović DA, Lević SM, Kostić A, Tešić ŽL, Nedović VA, Pešić MB (2019) Application of polyphenol-loaded nanoparticles in food industry. Nanomaterials. https://doi.org/10.3390/nano9 111629

Miralles P, van Gemert I, Chisvert A, Salvador A (2019) Stir bar sorptive-dispersive microextraction mediated by magnetic nanoparticles-metal organic framework composite: determination of $\mathrm{N}$-nitrosamines in cosmetic products. J Chromatogr A 1604:460465

Mishra R, Manral A (2021) Graphene functionalized starch biopolymer nanocomposites: fabrication, characterization, and applications. Graphene based biopolymer nanocomposites. Springer, pp 173-189

Mishra A, Kumar J, Melo JS, Sandaka BP (2021) Progressive development in biosensors for detection of dichlorvos pesticide: a review. J Environ Chem Eng 9(2):105067

Mofijur M, Siddiki SYA, Ahmed MB, Djavanroodi F, Fattah IR, Ong HC, Chowdhury M, Mahlia T (2020) Effect of nanocatalysts on the transesterification reaction of first, second and third generation biodiesel sources-A mini-review. Chemosphere 270:128642

Mohid SA, Bhunia A (2021) Combining antimicrobial peptides with nanotechnology: an emerging field in theranostics. Curr Protein Pept Sci 21(4):413-428

Murshid S, Gopinath KP, Prakash DG (2021) Current nanotechnology based solutions for sustainable wastewater treatment. Curr Anal Chem 17(2):166-184

Nasrollahzadeh M, Sajjadi M, Iravani S, Varma RS (2020) Green-synthesized nanocatalysts and nanomaterials for water treatment: current challenges and future perspectives. J Hazard Mater 401:123401

Nawaz MZ, Attique SA, Alshammari FA, Alhamdi HW, Alghamdi HA, Yan W (2021) A nanoinformatics approach to evaluate the pharmacological properties of nanoparticles for the treatment of Alzheimer's disease. Comb Chem High Throughput Screening. https://doi.org/10.2174/1386207324666210217145733

Ndlovu N, Mayaya T, Muitire C, Munyengwa N (2020) Nanotechnology applications in crop production and food systems. Int J Plant Breeding Crop Sci 7(1):624-634

Nehra M, Dilbaghi N, Marrazza G, Kaushik A, Sonne C, Kim K-H, Kumar S (2021) Emerging nanobiotechnology in agriculture for the management of pesticide residues. J Hazard Mater 401:123369

Nguyen VT, Vu QH, Pham TN, Trinh KS (2021) Antibacterial filtration using polyethylene terephthalate filters coated with copper nanoparticles. J Nanomater. https://doi.org/10.1155/2021/6628362

Nizami A-S, Rehan M (2018) Towards nanotechnology-based biofuel industry. Biofuel Res J 5(2):798

Oliveira AG, de Lara AJ, Montanha MC, Ogawa CYL, de Souza Freitas TKF, Moraes JCG, Sato F, Lima SM, da Cunha Andrade LH, Hechenleitner AAW (2021) Wastewater treatment using 
Mg-doped $\mathrm{ZnO}$ nano-semiconductors: a study of their potential use in environmental remediation. J PhotochemPhotobiol A Chem 407:113078

Ozogul F, Elabed N, Ceylan Z, Ocak E, Ozogul Y (2021) Nano-technological approaches for plant and marine-based polysaccharides for nano-encapsulations and their applications in food industry. Elsevier, pp 187-236

Paiva-Santos AC, Herdade AM, Guerra C, Peixoto D, Pereira-Silva M, Zeinali M, Mascarenhas-Melo F, Paranhos A, Veiga F (2021) Plant-mediated green synthesis of metal-based nanoparticles for dermopharmaceutical and cosmetic applications. Int J Pharm 597:120311

Patel RM, Dahane TM, Godbole S, Kambala SS, Mangal K (2020) Applications of nanotechnology in prosthodontics. J Evol Med Dent Sci 9(47):3566-3572

Patra Shahi M, Kumari P, Mahobiya D, Kumar Shahi S (2021) Chapter 4-nano-bioremediation of environmental contaminants: applications, challenges, and future prospects. In: Kumar V, Saxena G, Shah MP (eds) Bioremediation for environmental sustainability. Elsevier, pp 83-98

Paunovska K, Loughrey D, Sago CD, Langer R, Dahlman JE (2019) Using large datasets to understand nanotechnology. Adv Mater 31(43): 1902798

Peer D, Karp JM, Hong S, Farokhzad OC, Margalit R, Langer R (2020) Nanocarriers as an emerging platform for cancer therapy. Nanoenabled medical applications. Jenny Stanford Publishing, pp $61-91$

Rabiee N, Bagherzadeh M, Ghasemi A, Zare H, Ahmadi S, Fatahi Y, Dinarvand R, Rabiee M, Ramakrishna S, Shokouhimehr M (2020) Point-of-use rapid detection of sars-cov-2: nanotechnology-enabled solutions for the COVID-19 pandemic. Int J Mol Sci 21(14):5126

Raghav S, Yadav PK, Kumar D (2020) Nanotechnology for a sustainable future. Handbook of nanomaterials for manufacturing applications. Elsevier, pp 465-492

Razavi R, Kenari RE, Farmani J, Jahanshahi M (2020) Fabrication of zein/alginate delivery system for nanofood model based on pumpkin. Int J Biol Macromol 165(Pt B):3123-3134

Reshmy R, Philip E, Madhavan A, Sindhu R, Pugazhendhi A, Binod P, Sirohi R, Awasthi MK, Tarafdar A, Pandey A (2021) Advanced biomaterials for sustainable applications in the food industry: updates and challenges. Environ Pollut 283:117071

Rezaei M, Shokuhfar A, Shahcheraghi N (2021) Preparation and photocatalytic performance of flower-shaped $\mathrm{Zno} / \mathrm{GO} / \mathrm{Fe}_{3} \mathrm{O}_{4}$ on degradation of rhodamine B. Defect and diffusion forum. Trans Tech Publications, pp 161-172

Roco MC, Bainbridge WS (2013) Converging technologies for improving human performance: nanotechnology, biotechnology, information technology and cognitive science. Springer Science Business Media

Rottenberg S, Disler C, Perego P (2021) The rediscovery of platinumbased cancer therapy. Nat Rev Cancer 21(1):37-50

Rovera C, Ghaani M, Farris S (2020) Nano-inspired oxygen barrier coatings for food packaging applications: an overview. Trends Food Sci Technol 97:210-220

Ruan X, Liu D, Niu X, Wang Y, Simpson CD, Cheng N, Du D, Lin Y (2019) 2D Graphene oxide/Fe-MOF nanozyme nest with superior peroxidase-like activity and its application for detection of woodsmoke exposure biomarker. Anal Chem 91(21):13847-13854

Saari NHM, Chua LS (2020) Nano-based products in beverage industry. Nanoengineering in the beverage industry. Elsevier, pp $405-436$

Sahani S, Sharma YC (2020) Advancements in applications of nanotechnology in global food industry. Food Chem 342:128318
Sahu J, Karri RR, Zabed HM, Shams S, Qi X (2021) Current perspectives and future prospects of nano-biotechnology in wastewater treatment. Sep Purif Rev 50(2):139-158

Saidi MZ, El Moujahid C, Pasc A, Canilho N, Delgado-Sanchez C, Celzard A, Fierro V, Kouitat-Njiwa R, Chafik T (2021) Enhanced tribological properties of wind turbine engine oil formulated with flower-shaped MoS2 nano-additives. Colloids Surfaces A 620:126509

Sajjadi M, Ahmadpoor F, Nasrollahzadeh M, Ghafuri H (2021) Ligninderived (nano) materials for environmental pollution remediation: current challenges and future perspectives. Int J Biol Macromol 178:394-423

Sakulwech S, Lourith N, Ruktanonchai U, Kanlayavattanakul M (2018) Preparation and characterization of nanoparticles from quaternized cyclodextrin-grafted chitosan associated with hyaluronic acid for cosmetics. Asian J Pharm Sci 13(5):498-504

Saleh TA (2018) Nanotechnology in oil and gas industries. Springer, Cham

Saleh TA (2020) Nanomaterials: classification, properties, and environmental toxicities. Environ Technol Innov 20:101067

Samrot AV, Sahithya CS, Selvarani J, Purayil SK, Ponnaiah P (2020) A review on synthesis, characterization and potential biological applications of superparamagnetic iron oxide nanoparticles. Curr Res Green Sust Chem 4:100042

Sánchez-Rubio F, Soria-Meneses PJ, Jurado-Campos A, BartolomeGarcia J, Gomez-Rubio V, Soler AJ, Arroyo-Jimenez M, Santander-Ortega M, Plaza-Oliver M, Lozano M (2020) Nanotechnology in reproduction: vitamin $\mathrm{E}$ nanoemulsions for reducing oxidative stress in sperm cells. Free Radical Biol Med 160:47-56

Santos AC, Morais F, Simões A, Pereira I, Sequeira JAD, Pereira-Silva M, Veiga F, Ribeiro A (2019) Nanotechnology for the development of new cosmetic formulations. Expert Opin Drug Deliv 16(4):313-330

Séby F (2021) Metal and metal oxide nanoparticles in cosmetics and skin care products. Elsevier

Selivanovitch E, Douglas T (2019) Virus capsid assembly across different length scales inspire the development of virus-based biomaterials. Curr Opin Virol 36:38-46

Sharma A, Singh G, Arya SK (2021) Biofuel cell nanodevices. Int J Hydrogen Energy 46(4):3270-3288

Singh R, Misra V, Mudiam MKR, Chauhan LKS, Singh RP (2012) Degradation of $\gamma-\mathrm{HCH}$ spiked soil using stabilized Pd/Fe0 bimetallic nanoparticles: pathways, kinetics and effect of reaction conditions. J Hazard Mater 237-238:355-364

Subhedar DG, Patel YS, Ramani BM, Patange GS (2021) An experimental investigation on the effect of $\mathrm{Al}_{2} \mathrm{O}_{3}$ /cutting oil based nano coolant for minimum quantity lubrication drilling of SS 304. Cleaner Eng Technol 3:100104

Ta Q, Ting J, Harwood S, Browning N, Simm A, Ross K, Olier I, AlKassas R (2021) Chitosan nanoparticles for enhancing drugs and cosmetic components penetration through the skin. Eur J Pharm Sci 160:105765

Tan H, Wang C, Li H, Peng D, Zeng C, Xu H (2020) Remediation of hexavalent chromium contaminated soil by nano-FeS coated humic acid complex in combination with $\mathrm{Cr}$-resistant microflora. Chemosphere 242:125251

Tang C-H (2021) Assembly of food proteins for nano-encapsulation and delivery of nutraceuticals (a mini-review). Food Hydrocoll 117:106710

Tavakoli N, Divsalar A, Haertlé T, Sawyer L, Saboury AA, Muronetz V (2021) Milk protein-based nanodelivery systems for the cancer treatment. J Nanost Chem 11:483-500

Thakkar A, Raval A, Chandra S, Shah M, Sircar A (2020) A comprehensive review of the application of nano-silica in oil well cementing. Petroleum 6(2):123-129 
Thangadurai D, Sangeetha J, Prasad R (2020) Nanotechnology for food, agriculture, and environment. Springer International Publishing

Thirugnanam C, Dharmaprabhakaran T, Kalaimurugan K, Somasundaram D, Kumar AV, Ali MMJ (2021) Emission analysis of Palmyrah seed oil bio-diesel with $\mathrm{NiO}$ nano-particles on CI engine. Mater Today Proc. https://doi.org/10.1016/j.matpr.2021.01.87

Thomas S, Kumar Mishra P, Talegaonkar S (2015) Ceramic nanoparticles: fabrication methods and applications in drug delivery. Curr Pharm Des 21(42):6165-6188

Tiwari K, Singh R, Negi P, Dani R, Rawat A (2021) Application of nanomaterials in food packaging industry: a review. Mater Today Proc. https://doi.org/10.1016/j.matpr.2021.01.385

Tonk R (2021) The science and technology of using nano-materials in engine oil as a lubricant additives. Mater Today Proc 37:3475-3479

Usman M, Farooq M, Wakeel A, Nawaz A, Cheema SA, Ur Rehman H, Ashraf I, Sanaullah M (2020) Nanotechnology in agriculture: current status, challenges and future opportunities. Sci Total Environ 721:137778

Valencia PM, Farokhzad OC, Karnik R, Langer R (2020) Microfluidic technologies for accelerating the clinical translation of nanoparticles. Nano-enabled medical applications. Jenny Stanford Publishing, pp 93-112

Vázquez-Núñez E, Molina-Guerrero CE, Peña-Castro JM, FernándezLuqueño F, de la Rosa-Álvarez M (2020) Use of nanotechnology for the bioremediation of contaminants: a review. Processes 8(7):826

Visentin C, da Silva Trentin AW, Braun AB, Thomé A (2020) Nano scale zero valent iron production methods applied to contaminated sites remediation: an overview of production and environmental aspects. J Hazard Mater 410:124614

Wang D, Chen Y (2016) Critical review of the influences of nanoparticles on biological wastewater treatment and sludge digestion. Crit Rev Biotechnol 36(5):816-828

Wang Y, Zhang G (2020) The preparation of modified nano-starch and its application in food industry. Food Res Int 140:110009

Wang S, Chen Y, Wang S, Li P, Mirkin CA, Farha OK (2019) DNAfunctionalized metal-organic framework nanoparticles for intracellular delivery of proteins. J Am Chem Soc 141(6):2215-2219

Wang Y, Chen Y, Hu Y, Fang X (2020) Site-specific covalent labeling of large RNAs with nanoparticles empowered by expanded genetic alphabet transcription. Proc Natl Acad Sci 117(37):22823-22832

Wang F, Chang R, Ma R, Tian Y (2021) Eco-friendly and superhydrophobic nano-starch based coatings for self-cleaning application and oil-water separation. Carbohydr Polym 271:118410

Weijie M, Chongnv W, Xuming P, Weixin J, Yuhang W, Benhui S (2020) TiO2 nanoparticles and multi-walled carbon nanotubes monitoring and bioremediation potential using ciliates Pseudocohnilembus persalinus. Ecotoxicol Environ Saf 187:109825

Xu B, Liu C, Sun H, Wang X, Huang F (2020) Oil-in-water Pickering emulsions using a protein nano-ring as high-grade emulsifiers. Colloids Surfaces B 187:110646
Yadwade R, Gharpure S, Ankamwar B (2021) Nanotechnology in cosmetics pros and cons. Nano Express 2(2):022003

Yang Y, Li B, Peng J, Lei Z, Zhu E, Zhang X, Feng X, Mi Y (2021) The demulsification of crude oil emulsion driven by a natural lotus leaf grafted with nano-SiO2. J Environ Chem Eng 9(4):105586

Yao L, Ouyang L, Lv J, Dai P, Zhu L (2021) Rapid and sensitive SERS detection of food contaminants by using nano-Ag aggregates with controllable hydrophobicity. Microchem J 166:106221

Yue T, Liu J, Yang Y, Chen S (2021) Feasibility of cleaning As-and U-containing soil of a gold mine by using biologically nano-sized FeS: implications for soil remediation technology. Environ Technol Innov. https://doi.org/10.1016/j.eti.2021.101775

Zahed MA, Revayati M, Shahcheraghi N, Maghsoudi F, Tabari Y (2021a) Modeling and optimization of biodiesel synthesis using $\mathrm{TiO} 2-\mathrm{ZnO}$ nanocatalyst and characteristics of biodiesel made from waste sunflower oil. Curr Res Green Sustain Chem 4:100223

Zahed MA, Movahed E, Khodayari A, Zanganeh S, Badamaki M (2021b) Biotechnology for carbon capture and fixation: critical review and future directions. J Environ Manag 293:112830

Zhang S, Yao T, Wang S, Feng R, Chen L, Zhu V, Hu G, Zhang H, Yang G (2019a) Upconversion luminescence nanoparticles-based immunochromatographic assay for quantitative detection of triamcinolone acetonide in cosmetics. Spectrochim Acta Part A Mol Biomol Spectrosc 214:302-308

Zhang X, Wu D, Zhou X, Yu Y, Liu J, Hu N, Wang H, Li G, Wu Y (2019b) Recent progress in the construction of nanozyme-based biosensors and their applications to food safety assay. TrAC Trends Analyt Chem 121:115668

Zhang SS, Bilal M, Zdarta J, Cui JD, Kumar A, Franco M, Ferreira LFR, Iqbal HMN (2021) Biopolymers and nanostructured materials to develop pectinases-based immobilized nano-biocatalytic systems for biotechnological applications. Food Res Int 140:17

Zhao R, Heng M, Chen C, Li T, Shi Y, Wang J (2021) Catalytic effects of Al2O3 nano-particles on thermal cracking of heavy oil during in-situ combustion process. J Pet Sci Eng. https://doi.org/10. 1016/j.petrol.2021.108978

Zhironkin S, Demchenko S, Kayachev G, Taran E, Zhironkina O (2019) Convergent and nature-like technologies as the basis for sustainable development in the 21st Century. In: E3S Web of Conferences. EDP Sciences, p 03008

Zhou M, Hou T, Li J, Yu S, Xu Z, Yin M, Wang J, Wang X (2019) Selfpropelled and targeted drug delivery of poly(aspartic acid)/Ironzinc microrocket in the stomach. ACS Nano 13(2):1324-1332

Zhou Y, Wu X, Zhong X, Reagen S, Zhang S, Sun W, Pu H, Zhao JX (2020) Polymer nanoparticles based nano-fluid for enhanced oil recovery at harsh formation conditions. Fuel 267:117251

Zhu L, Tong L, Zhao N, Li J, Lv Y (2019) Coupling interaction between porous biochar and nano zero valent iron/nano $\alpha$-hydroxyl iron oxide improves the remediation efficiency of cadmium in aqueous solution. Chemosphere 219:493-503 